\title{
GENERAL TOPOLOGICAL PROPERTIES OF SWITCHING STRUCTURES
}

\author{
SLOBODAN ĆUK \\ California Institute of Technology \\ Pasodena, California
}

\section{ABSTRACT}

Investigation of a wide variety of switching converter topologies culminates in the establishment of the most general correlation between the converter topologies--the duality relationships. The recognition of this general law leads to a number of new results: new converter topologies generated by the application of the duality transkormation to the existing converter configurations, the discovery of the new mode of converter operation (discontinuous capacitance voltage mode) as well as significantly improved understanding of the existing converters and their equivalent circuit models.

\section{INTRODUCTION}

In the past decade many new switching configurations have been proposed, such as the Venable [1], Ćuk [2, 3], Weinberg [4], SEPIC [5] (Be11-Lab), and many others [6]. They all have in common the same functional goal of achieving dc-to-dc conversion, although that goal is obtained through a number of different topological structures. A great variety of possible interconnections of switches and storage elements (inductors, capacitors, and transformers) is still possible as further emphasized by the loosely defined switching converter configuration in Fig. 1a. The fundamental question then becomes how these, what at first may appear to be completely unrelated topologies, can be correlated? To answer this question a variety of current1y known switching converters is investigated in a search for establishment of the most general topological correlation among them. Hence, as is often the case, new innovative results are obtained by following an inductive approach. Small and separate pieces of the complete picture are painstakingly collected over the years and their proper placement in the overall mosaic attempted. However, as the knowledge and understanding of various parts progresses, at a certain stage the cumulative insight gained becomes sufficient to contemplate the overall mosaic. The development of the Power Electronics field has matured and progressed to the point where the visualization of such general concepts has now become a reality.

This work was sponsored by the office of Naval Research, Washington, DC under the contract N00014-78-C-0757--"Power Electronics Systems."
The establishment of such general laws and concepts is in any field a very difficult task, which is often hindered by the lack of knowledge of some important links, and Power Electronics is no exception. However, some recent results have provided a key to such a generalization process. In particular, the discovery of the new optimum topology (Cuk) switching dc-to-dc converter [7], has for the first time uncovered the existence of a new class of switching converters based on capacitive energy transfer, as opposed to the usual inductive energy transfer. This has brought attention to the dual nature of the two energy transfer mechanisms and the dual nature of the switching mechanism topologies $[2,3]$. When the constant current source is included as an alternative converter input source, the last remaining missing link is discovered and duality between complete converter topologies is established as a general law as postulated in Fig. 1 ( $a \& b)$. As seen in Fig. 1, the switching converters indeed consist of dual component inductors and capacitors, open and closed switches, input voltage and current

switching dc-to-dc converters

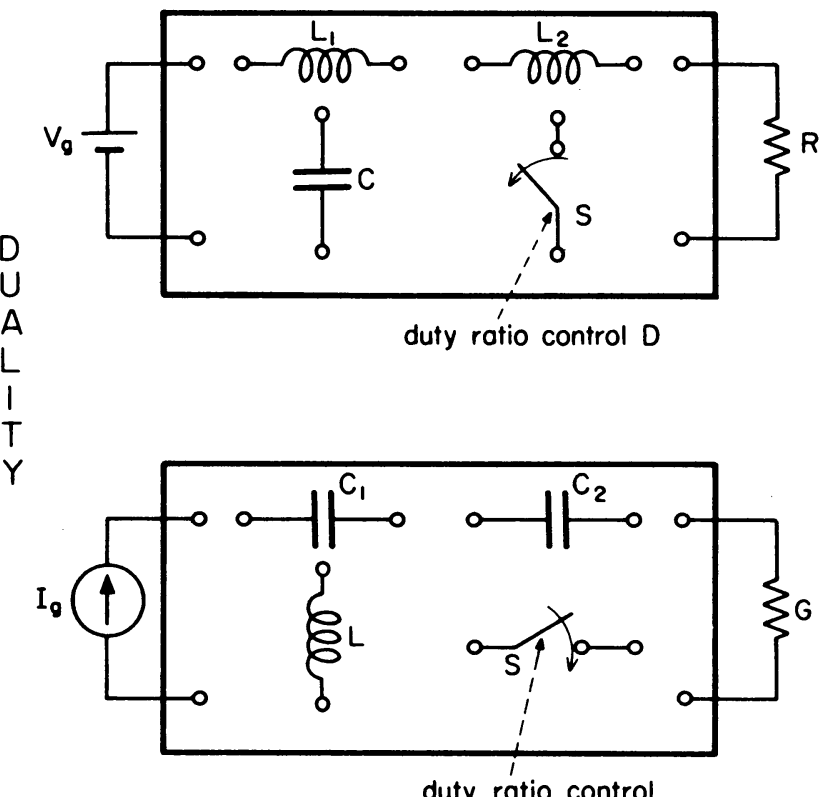

Fig. 1 Duality is postulated as the most general relationship among switching structures 
sources (although the latter one has been largely neglected in the past), load resistance and load conductance. The dual nature of converter topologies has been until now largely obscured by complex switching mechanisms and inductive energy transfer only.

After a brief review of properties of dual networks and an algorithm for their construction in Section 2, the duality among the four basic switching converter types is established in Section 3 .

An extension of the duality to switching converters which contain transformers is presented in Section 4, and a special switching configuration invariant under the duality transformation is uncovered.

Once the duality is established as the firm topological correlation, a number of new results are easily deduced in Sections 5 and 6 by use of the powerful duality principle. In Section 5, the usual criteria for determination of dc conditions, the so called volt-sec balance on inductors, is complemented by an equally important amp-sec (charge balance) criterion for the converters based on the capacitive energy transfer. The duality is furthermore extended to include both dc (steadystate) as well as dynamic (ac small-signal) properties through use of the equivalent circuit approach of modelling switching converters.

The duality principle leads in Section 6 to the discovery of a new mode of switching converter operation. Quantitative results are obtained for this new mode of operation for both dc (steadystate) and (ac) dynamic performance very easily by direct use of duality principle.

Some interesting correlations which exist among the duality and two other topological properties--the inversion and the symetry are explored in Section 7.

Finally, in Section 8 the duality concept is extended to switching regulators.

\section{REVIEW OF DUAL GRAPHS AND NETWORKS}

The following is a concise summary of the properties of dual graphs and networks, which is sufficient for understanding the subsequent derivations in the following sections. More detailed expositions of duality theory as applied to graphs and electric networks can be found in many standard textbooks such as $[8,9]$.

Duality theory is generally limited to the special class of graphs called planar graphs. A graph G is said to be a planar graph if it can be drawn oh a plane in such a way that no two branches intersect at a point which is not a node. For example, graph $G$ in Fig $2 a$ is a planar graph, whereas graph $G_{n}{ }^{p}$ in Fig. $2 b$ is not a planar graph. a)

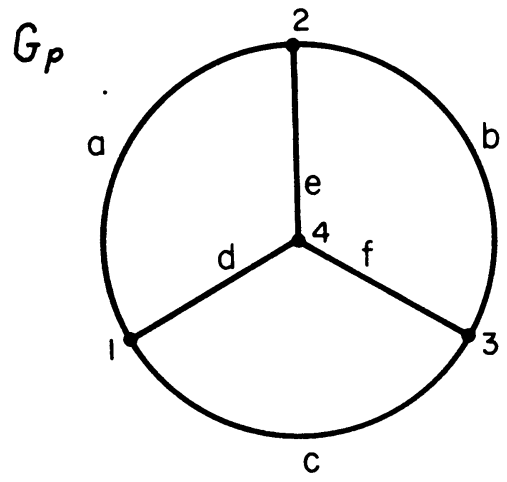

b)

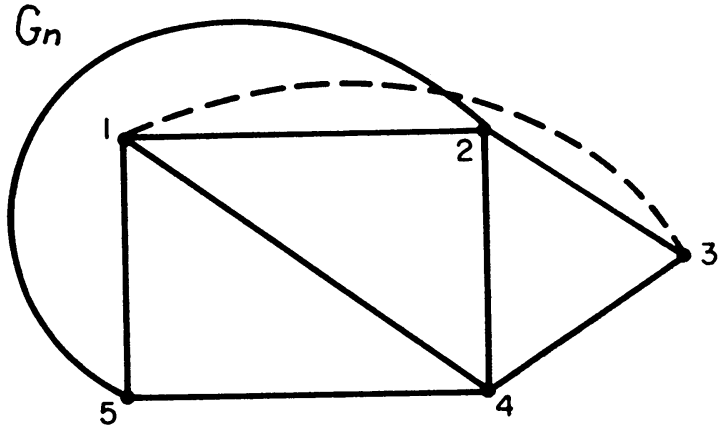
Fig. 2 Examples of planar $(a)$ and nomplanar (b)
graphs

In a planar graph, however, meshes and outer meshes are distinguished. Any closed loop of the planar graph for which there is no branch in its interior is a mesh. For example, loops ebf, dfc, aed are meshes in the planar graph Gp of Fig. 2a. Analogously, a loop which contains no branches in its exterior is called an outer mesh, like loop abc in the planar graph G of Fig. 2a. In this Review section the star nbtation (*) is used to designate the dual graphs, networks and dual components to facilitate easier recognition of duality relationships. However, in the remaining sections it will be left out, since the recognition of dual components will by then be mastered.

Two planar graphs $G$ and $G^{*}$ are dual graphs if: a) there is a one-to-one correspondence between the meshes, of $G$ (including the outer mesh) and the nodes of $G$, and vice versa, and b) there is a one-to-one correspondence between the branches of each graph, such that whenever two meshes of one graph have a branch in common, the corresponding nodes of the other graph have the corresponding branch connecting these nodes.

For example, the graphs $G$ and $G^{*}$ of Fig. 3a are dual graphs, since the above correspondence can be easily established.

For two electrical networks $\mathrm{N}$ and $\mathrm{N}^{\star}$ to become dual, some additional properties are required. In addition to the graph concepts (meshes corresponding to nodes), the relationships between the dual 
a) graphs

$G$

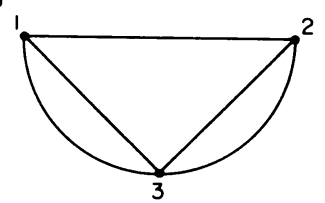

$\mathrm{G}^{*}$

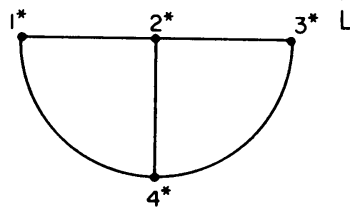

b) networks

N

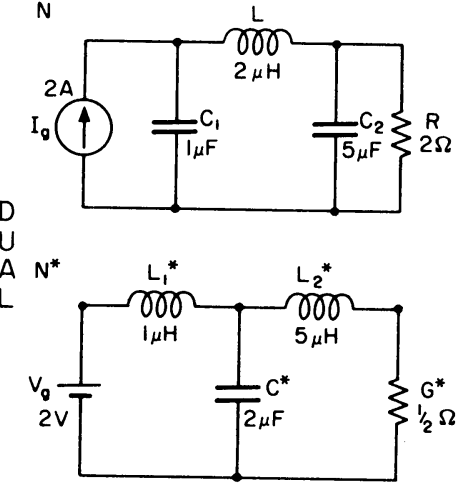

Fig. 3 Example of dual networks (b). and their corresponding graphs $(a)$

networks also involve the dual nature of the elements, that is, their electrical properties

(capacitors corresponding to inductors, voltage sources correnponding to current sources etc.). Therefore, networks $\mathrm{N}$ and $\mathrm{N}$ are dual networks if: a) they have dual topological graphs $G$ and $G$ b) the branch equation of a branch of $\mathrm{N}$ is obtained from its corresponding equation of $\mathrm{N}$ by performing the following substitutions;

$v \rightarrow j^{*}, j \rightarrow v^{*}, q \rightarrow \phi^{*}$ and $\phi \rightarrow q^{*}$

where $v, j, q$ and $\phi$ are branch voltage, current, charge and flux variations.

Thus, to a resistance of $\mathrm{R}$ ohms of $\mathrm{N}$ there corresponds a conductance of $\mathrm{G}$ mhos $(1 / \Omega)$ in $\mathrm{N}^{*}$, since $\mathrm{v}=\mathrm{Rj}$ branch relation is transformed into $j^{*}=G^{*} v^{*}$, where $G^{*}=1 / R$. Therefore, a resistance of $R$ ohms in the original network becomes resistance of $1 / R$ ohms in the dual network. Similarly from the inductor of $\mathrm{L}(\mu \mathrm{H})$ becomes a capacitor of $\mathrm{C}^{*}(\mu \mathrm{F})$ and vice versa as seen from the example in Fig. $3 \mathrm{~b}$. Also, the current source of I (Amperes) corresponds to a voltage source of $\mathrm{V}_{\mathrm{g}}$ (Volts) in the dual network. In summary, the following dual substitutions are in order:

$\mathrm{L} \rightarrow \mathrm{C}^{*}, \mathrm{C} \rightarrow \mathrm{L}^{*}, \mathrm{R} \rightarrow \mathrm{G}^{*}\left(\mathrm{G}^{*}=\frac{1}{\mathrm{R}}\right), \mathrm{I}_{\mathrm{g}} \rightarrow \mathrm{V}_{\mathrm{g}}{ }^{*}$

Let us now see how for a given planar graph or planar network the dual can be constructed.

\subsection{Algorithm for Dual Graph and Dual Network Construction}

The dual graph $G^{*}$ of a planar graph $G$ can be obtained if:

a) to each mesh of graph $G$, we associate a corresponding node of $G$, by placing it inside the mesh. Finally, an additional node is placed outside of graph G (in its exterior) which corresponds to the outer mesh of graph G;

b) for each branch, say $b$, of $G$ which is common to mesh $i$ and $j$, we associate $a_{\star}$ branch $b$ of $G^{*}$ which is connecting the nodes of $G^{*}$ corresponding to meshes $i$ and $j$ of $G$.

a) graphs
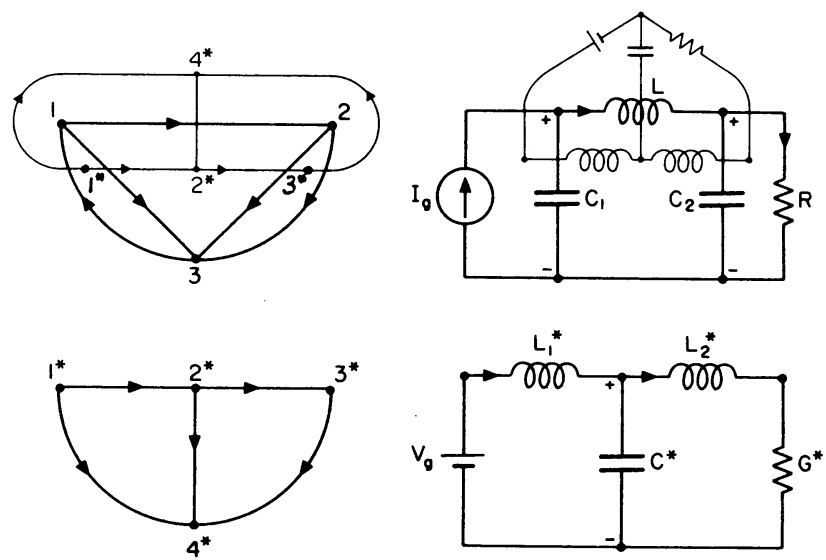

Fig. 4 Algorithm for dual graph and dual network construction

This construction is transparent from Fig. 4a which is also an example of oriented graphs. Given the orientations of the original graph $G$ branches, the orientation of corresponding dual branches is obtained by counterclockuise rotation of the original branches until they coincide with their dual branch directions, as also illustrated in Fig. $4 \mathrm{a}$.

The dual oriented network construction involves only the additional step of dual substitutions (1) and (2) in the corresponding dual branches, as also easily seen in Fig. $4 \mathrm{~b}$.

The mere construction of a dual network following this algorithm would have remained just an interesting and elegant topological correlation, had it not been intimately tied with a truly remarkable general law of nature--the duality principle.

\subsection{Duality Principle}

Since many of the results obtained in later sections will be based on the duality principle, not only some qualitatively new phenomena, but quantitative results as well, it requires a very careful definition [8]. The remarkable duality principle can be stated as:

Consider an arbitrary planar network $N$ and its dual network $N$. Let $S$ be any true statement concerning the behaviour of $N$. Let $S^{*}$ be the statement obtained from $S$ by replacing every graph theoretic word or phrase (node, mesh, loop, etc.) by its dual and every electrical quantity lvoftage, current, impedance, etc. by its dual. Then $S^{*}$ is a true statement concerning the behaviour of $N^{*}$.

In its abbreviated form limited to the relationship of its electrical parameters which will be very often used later, it can be stated in the form of the equivalence relation:

$S(j, v, q, \phi, L, C, Z) \rightrightarrows S^{*}\left(v^{*}, j^{*}, \phi^{*}, q^{*}, C^{*}, L^{*}, Y^{*}\right)$ 


\section{DUALITY IN SWITCHING DC-TO-DC CONVERTERS}

As also anticipated in the Introduction and illustrated in Fig. 1, in order fully to develop the duality relationships, the notion of a switching dc-to-dc current converter needs to be introduced first and its meaning clarified. In other words a constant current input source is postulated in addition to the usual constant voltage source.

\subsection{Switching Dc-To-DC Voltage and Current Converters}

Consider now the comparison of the conventional buck converter, with either constant voltage source as in Fig. $5 \mathrm{a}$, or constant current source as in $\mathrm{Fig}$. $5 \mathrm{~b}$. In either case, the inductance $\mathrm{L}$ is for simplicity large enough to result in practically dc current I at the output, with negligible switching ripple. Although the practical realization of the switching current converter is of no concern here, it may suffice to say that the constant current source $I$ may be voltage limited to prevent excessive rise ${ }^{g}$ of the voltage on the input capacitance $\mathrm{C}$ (for $\mathrm{S}$ at position $\mathrm{B}$ only). It is also assumed that ideal switch $S$ is in position A for interval DT and in position B for interval $\mathrm{D}^{\prime} \mathrm{T}_{\mathrm{S}}=(1-\mathrm{D}) \mathrm{T}_{\mathrm{S}}$, where $\mathrm{D}$ is the switch duty ratio and $T_{s}$ the switching period.

a)

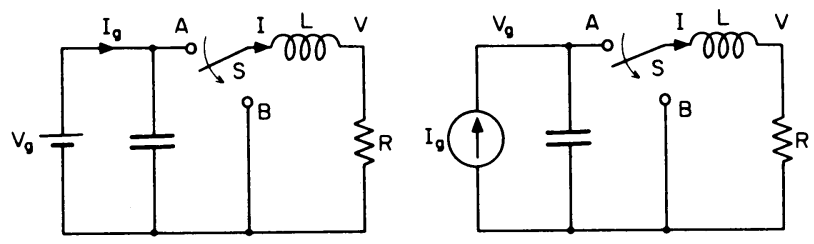

Fig. 5 Comparison of a switching voltage $(a)$ and a switching current converter (b)

We now concentrate on the principal features of the two converters in Fig. 5. For the voltage converter in Fig. $6 a$, we easily obtain in the ideal case:

$$
\begin{aligned}
& \frac{\bar{V}_{g}}{V_{g}}=\mathrm{D} \\
& \frac{\mathrm{I}}{\overline{\mathrm{I}}_{\mathrm{g}}}=\frac{1}{\mathrm{D}} \rightrightarrows \mathrm{I}_{\mathrm{g}}=\frac{\mathrm{D}^{2}}{\mathrm{R}} \mathrm{V}_{\mathrm{g}}
\end{aligned}
$$

Thus from (4), the voltage gain is only dependent on duty ratio $D$, but is independent of load $R$. However, the dc current $I$ drawn from the source is dependent on load $\mathrm{R}^{\mathrm{g}}$ as seen in (5). Therefore, the converter of Fig. 6a can be conveniently designated as a switching dc-to-dc voltage converter. On the other hand, for the converter in Fig. $6 \mathrm{~b}$ :

$$
\begin{aligned}
& \frac{\mathrm{I}}{\mathrm{I}_{\mathrm{g}}}=\frac{\mathrm{l}}{\mathrm{D}} \\
& \frac{\mathrm{V}}{\mathrm{v}_{\mathrm{g}}}=\mathrm{D} \rightrightarrows \mathrm{V}_{\mathrm{g}}=\frac{\mathrm{R}}{\mathrm{D}^{2}} \mathrm{I}_{\mathrm{g}}
\end{aligned}
$$

Here the current gain is independent of load $R$ as in (6), while both input and output voltage fluctuate to accomodate the change of load $R$. Thus, this converter can be conveniently designated as a switching dc-to-dc current converter. Hence the basic buck power stage operates as either a switching voltage or a current converter depending on the type of dc source applied.

\subsection{Duality Among the Four Basic Switching Converter Types}

Although it has not previously been demonstrated how a dual network of a planar network which contains switches can be found, it is relatively simple to resolve this problem. Consider, for example, a switching buck-type current converter more closely, which is for convenience again redrawn in Fig. 6a. For the two positions of switch $\mathrm{S}$ (for intervals $\mathrm{DT}$ and $\mathrm{D}^{\prime} \mathrm{T}$ respectively), the two switched networks of Fig. 65 are obtained. Each of the two switched networks of Fig. $6 \mathrm{~b}$ is a planar network, consisting of L, C, R and I. Thus a dual network for each of the two linear switched networks of Fig. 6b can easily be found following the algorithmic procedure outlined in Section 2 for dual network construction. By taking into account the orientation of the branches in Fig. 6b, the dual oriented networks are obtained in Fig. 6c. The two dual switched networks of Fig. 6c can now easily be redrawn as resulting from a single switching network in Fig. 6d for the two positions of its single-pole double-throw switch $S$.
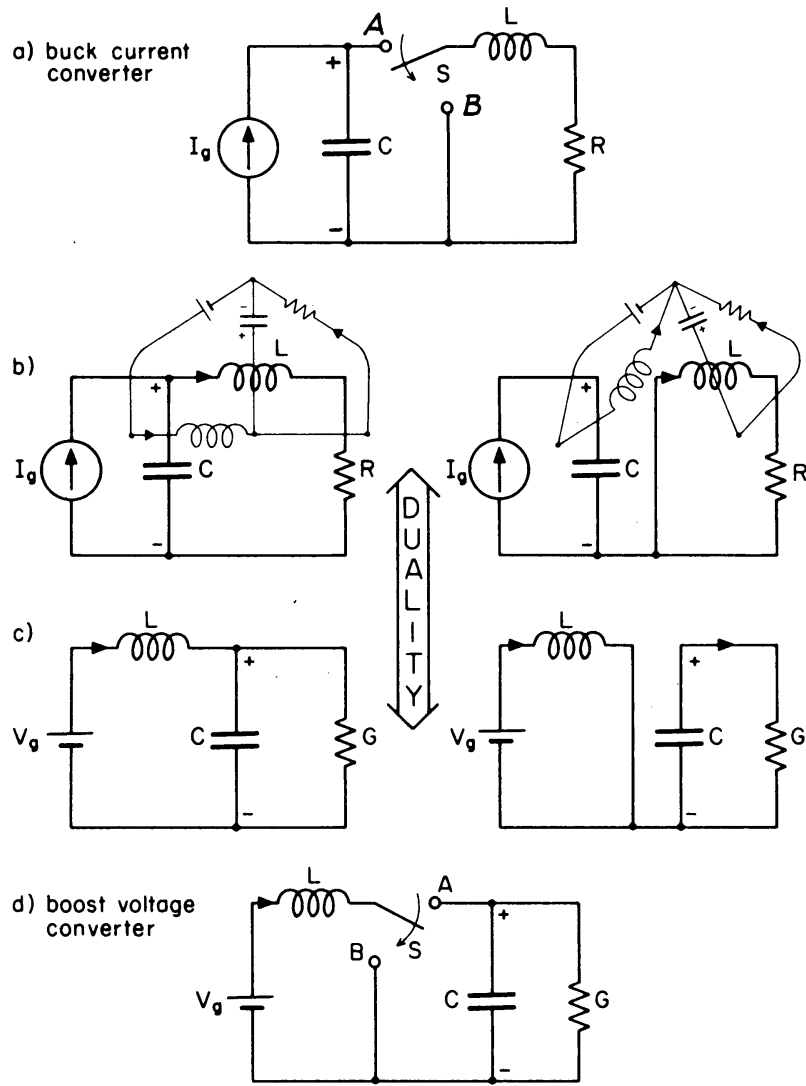

Fig. 6 Duality between the buck and the boost switching converters 
An important conclusion can now be made from Fig. 6. The familiar boost voltage converter is just a dual network to the buck current converter.

It should be also noted that in the two dual networks, the positions $A$ are the corresponding homologous switch positions. Note also that for the buck current converter only minimal configuration was chosen, and the usual output capacitance left out as not essential, as seen in Fig. 6 a. However, the inductor $\mathrm{L}$ is essential and leads in the dual network to capacitor $C$ which is likewise essential for boost voltage converter operation as in Fig. 6d.

By invoking the powerful duality principle (3) we can obtain directly the dc voltage gain of the boost converter from the dc current gain (6) of its dual buck converter as

$$
\frac{I}{I_{g}}\left(\begin{array}{l}
I \rightarrow V \\
I_{g} \rightarrow V_{g}
\end{array}\right)=\frac{V}{V_{g}}=\frac{1}{D}
$$

if the duty ratio of switch $\mathrm{S}$ in Fig. $6 \mathrm{~d}$ is referred to the corresponding position $A$. However, owing to practical realization of that switch by a bipolar transistor and diode, it is usually referred to position $B$ (on time of the transistor). Thus with the duty ratio defined with respect to $B$ in Fig. $6 d$, we get

$$
\left.\frac{\mathrm{V}}{\mathrm{V}_{\mathrm{g}}}\right|_{\mathrm{D} \rightarrow \mathrm{D}^{\prime}}=\frac{1}{\mathrm{D}^{\prime}}=\frac{1}{1-\mathrm{D}}
$$

which is the familiar dc gain of the boost converter. This is a first example which illustrates the powerful duality principle, and how the property of a dual network (here voltage gain), can be determined directly from the dual property of the original network (here current gain).

One is now immediately inspired to find dual switching converters to all known switching

structures. Once equipped with this powerful tool and method to generate dual switching structures, two goals may be achieved at the same time: a) the known switching converters can be correlated by a strong bond via duality correlation, and their comparative performance much better understood. In fact, later in Section 6 it will be shown how some new phenomena can be uncovered in existing converters based on the established duality relationships.

b) new, at present unknown switching configurations may be discovered, completing the set of all possible switching configurations.

Let us continue this exciting search with the conventional buck-boost converter being now the obvious next choice. Again as before for the buck converter we consider the conventional buck-boost converter as shown in Fig. 7a. Following the same algorithm for dual network construction, the dual switched networks of Fig. 7c are obtained from the original switched networks of buck-boost converter shown in Fig. 7b. Finally, the switching mechanism which leads to the two switched networks of Fig. $7 \mathrm{c}$ is reconstructed as switch $\mathrm{S}$ in the

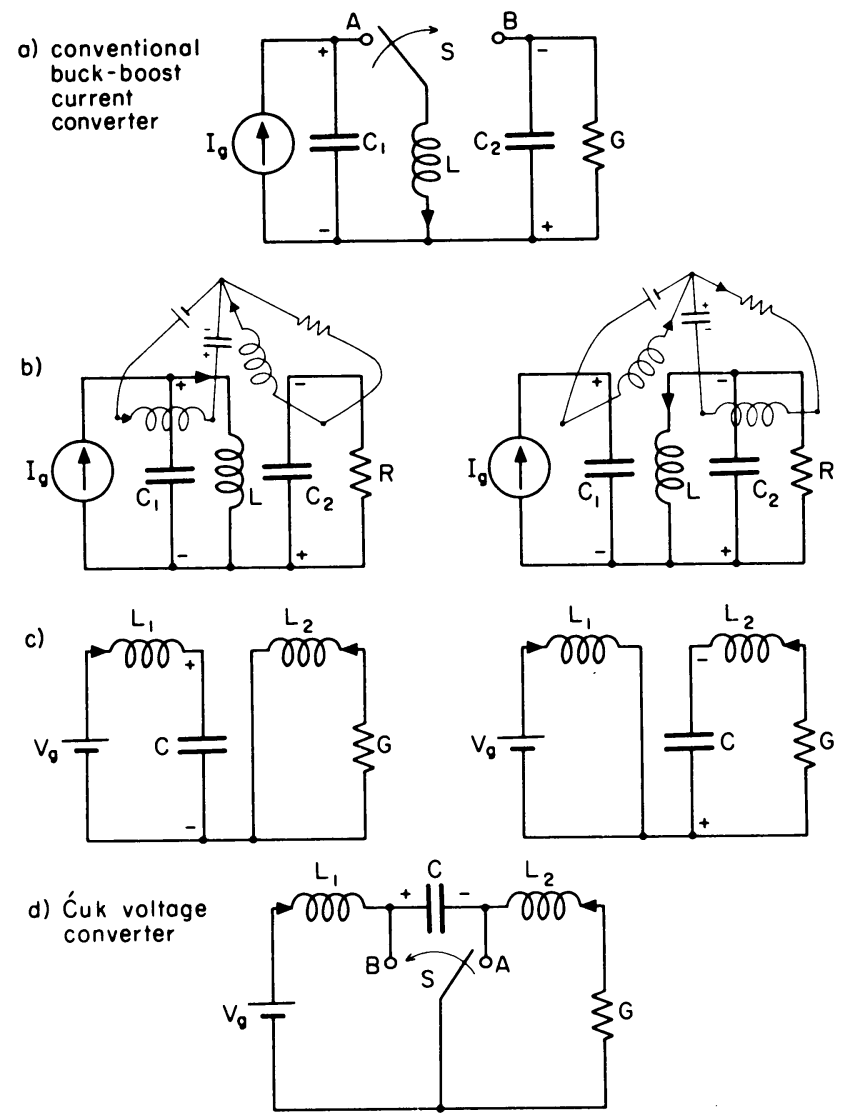

Fig. 1 Duality between the buck-boost and Cuk converters

switching converter of Fig. 7d. Note that here the use of oriented graphs in dual network construction is absolutely essential since only the proper polarity of capacitance $C$ such as that shown in Fig. 7c leads to the switch $S$ realization as in Fig. 7d. Had the orientation of branches not been used in the duality transformation, the final dual switched networks would leave an ambiguity as to whether the switch implementation is as in Fig. 7d, or as in the straightforward cascade connection of the boost converter followed by a buck (two switch realization) as shown later in Fig. 11 .

The following conclusion can now easily be made from Fig. 7. The dual network of the conventional buck-boost current converter is the new optimum topology (ćuk) voltage converter. This now suggests an alternative (deductive) path which could have been followed in the discovery of the new converter topology of Fig. $7 d$, had it not been discovered earlier following a different path. Nevertheless the original path of discovery $[2,3]$ followed quite natural steps of converter performance improvement (cascade of the boost converter followed by the buck converter, hence nonpulsating input and output currents) and simplification with high efficiency in mind (hence reduction of number of switches in a straightforward cascade connection). In any case, both that inductive path and 
the just-outlined deductive path (coming from the general observation of applicability of the duality principle to switching converters) lead to the same result--the new Cuk converter topology. Both approaches, however, emphasize the fact that a remaining fourth very important member of the family of basic switching converters was indeed missing.

The establishment of the duality between the two switching converter topologies permits now all properties and results found for the conventional buck-boost converter to be transferred as dual properties in the Cuk converter via the duality principle. Only some of the key essential features and properties will be emphasized here with the help of Fig. 8, while the detailed comparison will be given in Sections 5 and 6 . For example, the dc current gain of the buck-boost converter $\mathrm{I} / \mathrm{I}=\mathrm{D}^{\prime} / \mathrm{D}$ leads to the dc voltage gain of the dual cak converter as

$$
\frac{I}{I_{g}}\left(\begin{array}{lll}
I_{g} \rightarrow & V \\
I_{g}
\end{array}\right)=\frac{D^{\prime}}{D}
$$

when duty ratio $D$ is referred to homologous point $A$ in Fig. 7d. However, with respect to point $B$ as is the case in practice, the dc voltage gain becomes:

$$
\frac{\mathrm{V}}{\mathrm{V}}_{\mathrm{g}} \mid \mathrm{D} \leftrightarrow \mathrm{D}^{\prime}=\frac{\mathrm{D}}{\mathrm{D}^{\prime}}
$$

a)

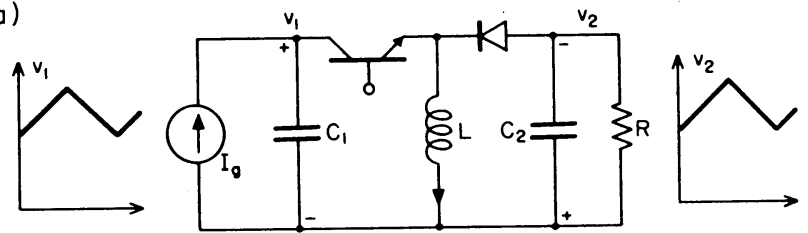

b)

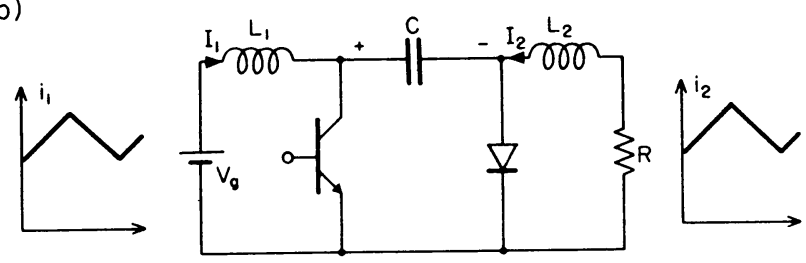

Fig. 8 Comparison of buck-boost and cuk converters

Comparison of the waveforms in Fig. 8 shows that the nonpulsating input and output voltage waveforms of the buck-boost current converter have been mapped by the duality transformation into the very desirable nonpulsating input and output currents of the Cuk voltage converter. In addition, to the inductive energy trans fer of the buck-boost converter, there corresponds a dual capacitive energy transfer of the Cuk converter since inductance is the only energy transferring device between input and output ports in the buck-boost converter and capacitance in the Cuk converter.
In fact, it is this duality of energy transferring mechanism which has prompted the search for the complete duality of two switching converter topologies and subsequently has led to the establishment of duality as a general concept for a wide class of switching converters.

This also becomes an important distinguishing feature of the buck-boost converter types, which are based on inductive energy transfor only, and the new Cuk converters which are primarily based on capacitive energy transfer, but are not limited to that type only, since some of their extensions (such as coupled-inductor $\hat{C} u k$ converter and single inductor Cuk converter) possess an additional inductive energy trans fer.

Let us now for completeness present an alternative method for the construction of dual networks for networks which contain switches. This method circumvents the need for construction of a dual network for each switch position and the subsequent reconstruction of the switching mechanism, but is rather carried out in a single duality transformation. For example, the switch action in the buck converter of Fig. 6a, can be modeled by the dependent voltage and current sources as shown in Fig. 9a, in which the variable a takes two discrete values: $\alpha=1$ for interval DT (switch $S$ in Fig. 6a in position $A$ ) and $\alpha=0$ for interval D'T (switch $\mathrm{S}$ in Fig. 6a in position B). The standard algorithm then results in the dual network shown in Fig. 9b.
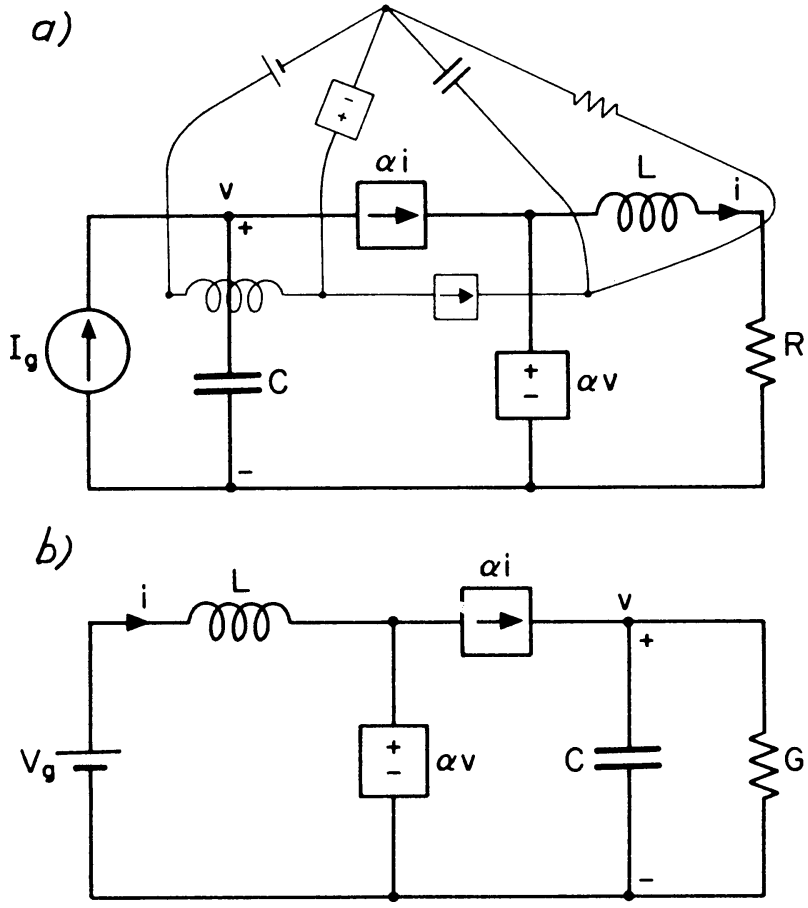

Fig. 9 An alternative approach for the construction of a dual to the switching converter of Fig. 6 a 
However, proper precaution has to be taken in transforming the controlling quantities of dependent sources (such as $i$ and $v$ in Fig. 9a) into their respective dual counterparts in Fig. $9 b$. For example, the current source in Fig. 9a is controlled by output current $i$, which in the dual network becomes a dependent voltage source controlled by the output voltage $v$ (dual to current i).

A somewhat more complex case of using this method is illustrated in Fig. 10, which gives an alternative dual construction to that of Fig. 7 .

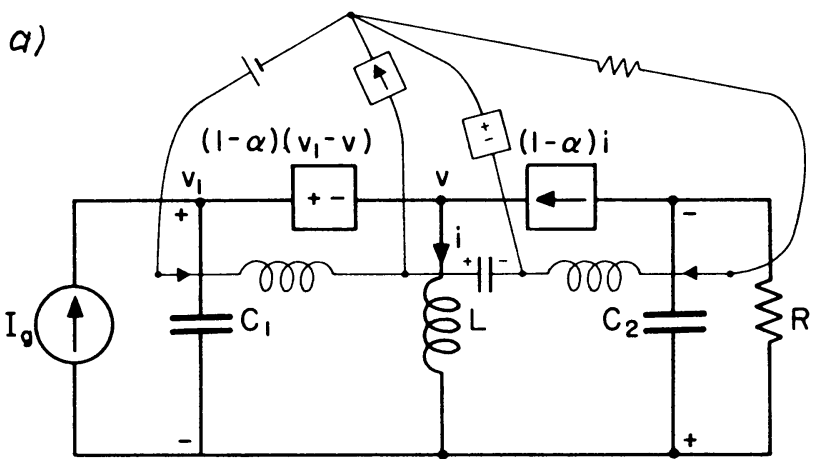

b)

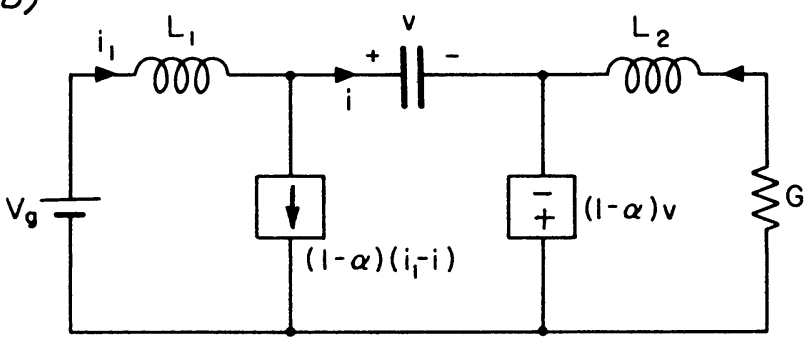

Fig. 10 An alternative approach for the construction of a dual to the switching converter of Fig. 7 a

Although presented so far for the singleswitch basic converters, the duality relationships are not limited to that and can be as easily implemented in multi-switch converters as shown next.

\subsection{Duality in Derived Switching Converters}

Following either of the two approaches it is easily shown that the cascade connection of the boost converter followed by the buck (Fig. 11b) is really a dual switching converter to the cascade connection of the buck converter followed by the boost converter (Fig. 11a). In fact, the reduction of the switches in the converter of Fig. 11a led to a conventional buck-boost converter (Fig. 7a), while a similar reduction of switches in Fig. 11b has led to the Cuk converter $[2,3]$. a)

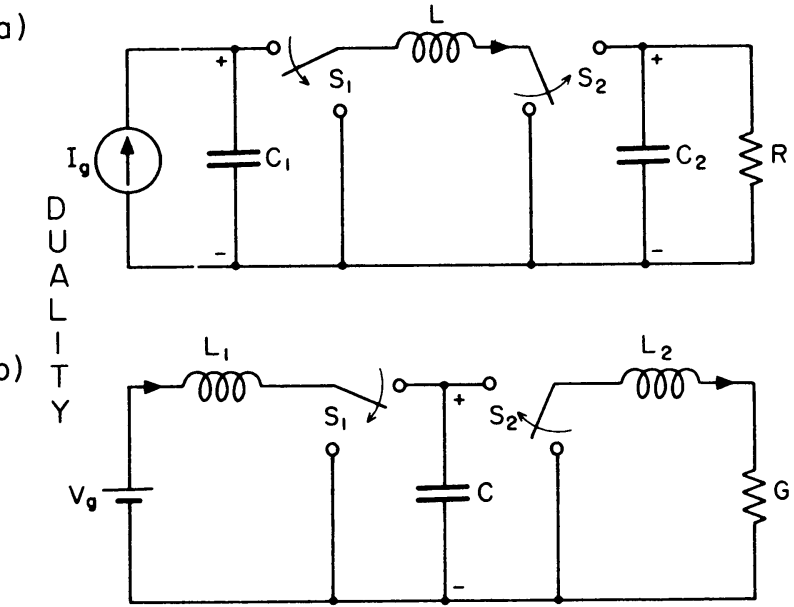

Fig. 11 Duality in switching converters with two ideal switches:

a) noninverting buck-boost

b) noninverting boost-buck

Note that in the general setting of Fig. 1 not all interconnections of storage elements and switches are allowed but only those which result in an effective low-pass filter nature, hence allowing the input dc component to pass to the output. How can then we be sure that the duality transformation will lead to the correct dc-to-dc converter topology? However, even the few given examples are sufficient to postulate the general conclusion:

The duality trans formation of any viable switching $d c-t o-d c$ converter topology results in an equally viable dc-to-dc converter topology.

This must be so, since from the duality principle, the dc current conversion is transformed into a dc voltage conversion, hence the dc conversion property is conserved. From the topological viewpoint any capacitance effectively in parallel is transformed into an effective series inductance and vice versa, hence the low-pass filter nature of the effective filtering is preserved.

Although the duality relationships are shown to be applicable to a relatively wide class of switching structures as exemplified by Fig. 1, they still do not include the transformers owing to the lack of the corresponding dual components. Let us now see how duality can be extended to circumvent this problem and still be useful in deriving new configurations from the converters containing transformers. 


\section{EXTENSION OF DUALITY TO SWITCHING CONVERTERS WITH TRANSFORMERS}

In many practical applications dc isolation between the input source and output load side is required, hence the importance of encompassing this class of converters into a more general and unified theory, such as the duality theory developed in the previous section. As an example, consider the converter of Fig. 12a introduced in [5] and known as SEPIC (Single Ended Primary Inductance Converter), whose transformer provides the isolation between input and output sides. The difficulty in applying the duality transformation to this structure lies in the fact that there is no proper dual component corresponding to an ac transformer. However, still some hidden avenues remain open for the application of the duality transformation.
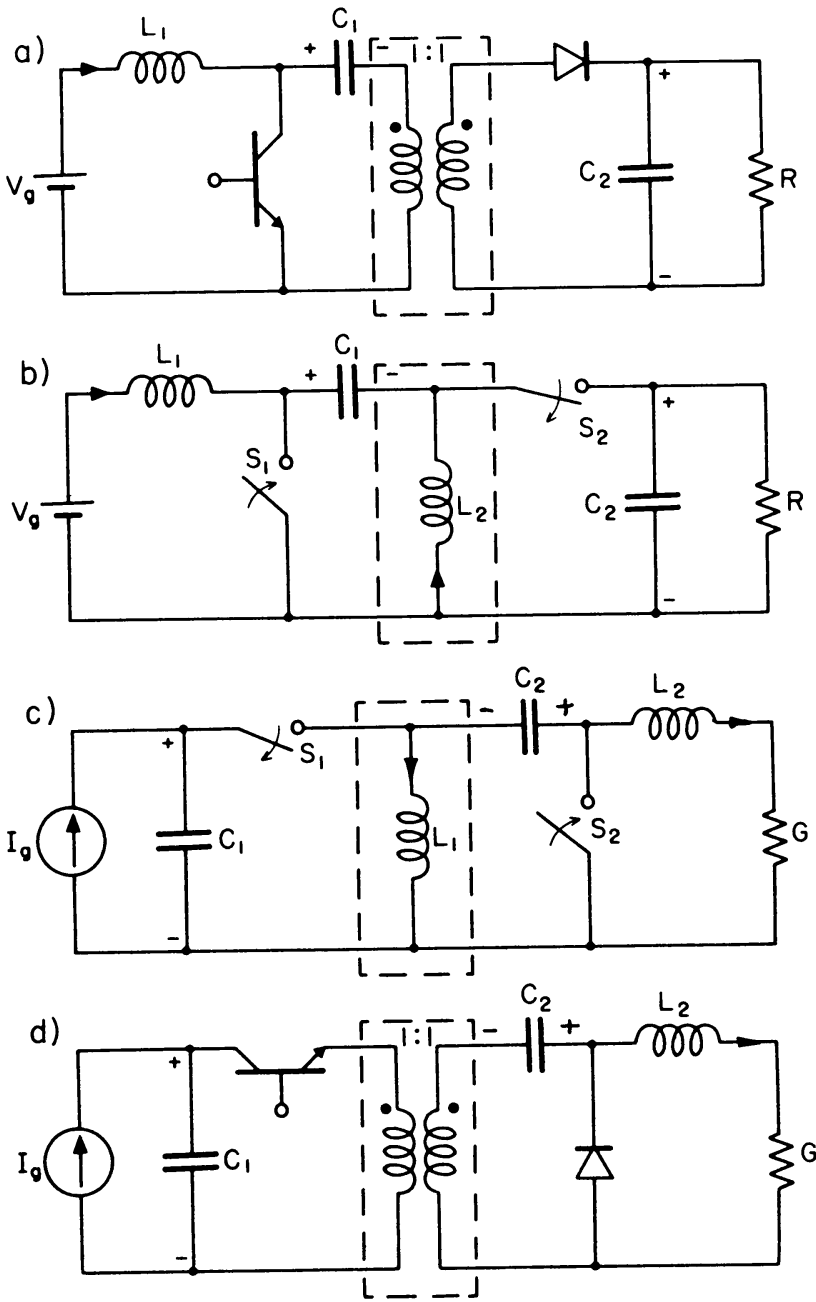

Fig. 12 Duality trans formation in switching converters with trans formers--SEPIC converter example
The transformer may, for example, be considered perfect, and hence replaced by its magnetizing inductance $\mathrm{L}_{2}$ model (leakage inductances zero) and the isolation property temporarily lost as in the intermediate step shown in Fig. 12b. In fact, by replacing the transformer w-th a single inductance, the main feature of the inductive energy transfer that the isolation transformer also performed is still preserved. However, this configuration with its transistor and diode being replaced by ideal synchronous switches $\mathrm{S}_{1}$ and $\mathrm{S}_{2}$ (Fig. 12b) is now in a form for direct duality transformation application, since it only consists of capacitors and inductors with no transformers. The dual switching converter to the converter of Fig. $12 \mathrm{~b}$ is then easily found as shown in Fig. 12c. The lost isolation property can now easily be recovered by replacing the inductor at the input with its more general transformer representation, thus resulting in the switching dc-to-dc converter of Fig. 12d in which the ideal switches have also been replaced by the transistor and diode. Thus, with the special intermediate transformations in mind (which preserves the original inductive energy transfer) the two converters of Fig. 12a and Fig. $12 \mathrm{~d}$ may be considered dual, even though they both have dc isolating transformers among their components.

It is interesting to point out that the front end of the SEPIC converter has the same boost-like form as the front end of the dc isolated Cuk converter shown in Fig. 13, while the just-derived converter of Fig. 12d has the same buck-1ike output form as the dc isolated converter of Fig. 13. However, their features, especially regarding the isolation transformers, are markedly different [10], including opposite isolation transformer polarity in converter of Fig. 13.

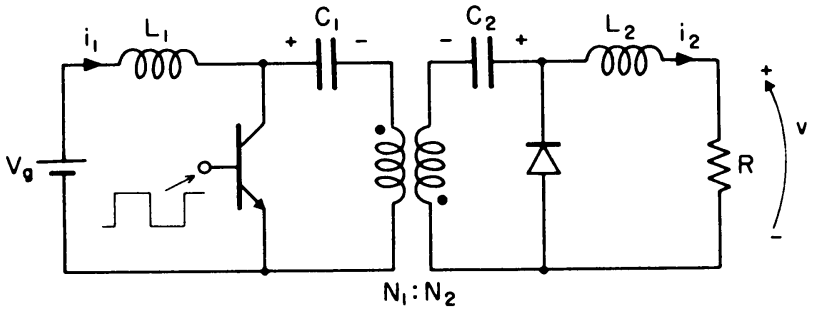

Fin. 13 DC isolated Ćuk converter

Lew us now take another example of the switching converter containing the transformer, which is however not used to provide the isolation, but rather to achieve some other benefits. Namely, recently a new general technique of magnetically coupling the inductors in some switching converters is shown $[11,12]$ to lead to further improved performance, with even the possibility of achieving a zero-current ripple at a selected end.

Specifically, the unique features of the basic Cuk converter (Fig. 8b) allowed the coupling of the input and output inductors on the same core and resulted in the coupled-inductor Cuk converter of Fig. 14. Magnetic coupling thus provided an additional inductive energy transfer as seen from Fig. 14 . 


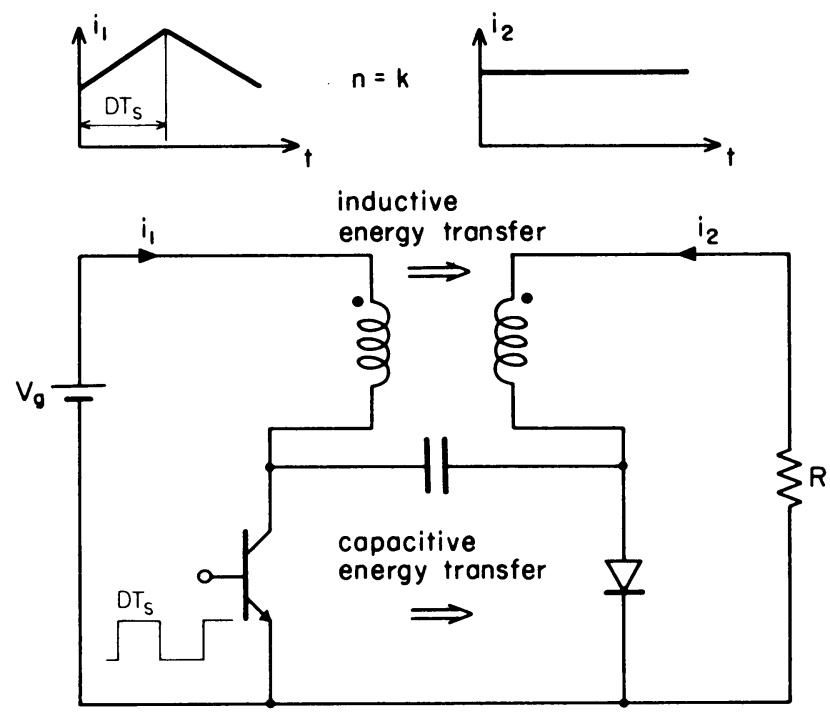

Fig. 14 Coupled-inductor Cuk converter further reduces current ripple at both inpw: and output

For the first time a switching converter was available (Fig. 14) with both capacitive and inductive energy transfor between the input and output ports, as compared to the conventional converters which are based on the inductive energy transfer only (such as buck-boost converter of Fig. 8 a for examplel.

Thus, it should come as no surprise that both input and output current ripples have been reduced from the original uncoupled case (Fig. 8b). By proper adjustment of the transformer (coupledinductors) effective turns ratio with respect to its coupling coefficient, eyen zero current ripple at either input or output side has been demonstrated [12]. Furthermore, the same benefits are available by coupling the inductors in the isolated Ćuk converter of Fig. 13 [7] as practically demonstrated in [13].

The coupled-inductor version of Fig. 14 has in effect an ac transformer and hence is not yet in a form appropriate for duality transformation. It is however a relatively simple matter to see that the coupled-inductor Cuk converter can be redrawn as in Fig. 16a, such that the coupled inductors have a common junction. Just as the coupled-inductor Cuk converter is in its most general form in Fig. 16a, so is the conventional transformer-coupled buckboost ( flyback) converter of Fig. 15a. In the special case of 1:1 turns ratio, the transformer in Fig. 15a can be replaced by a single inductor and the nonisolated buck-boost of Fig. 15b obtained. Similarly, for the special case of $1: 1$ turns ratio in the coupled-inductor Cuk converter of Fig. 16a the coupled inductors can be replaced by a single inductor, resulting in the special case of coupled inductors--the single inductor cuk converter of

Fig. 16b. Note that the presence of both inductive and capacitive energy transfer between the input and output ports is now even more transparent than in its more general-coupled inductor version of Fig. 14 .
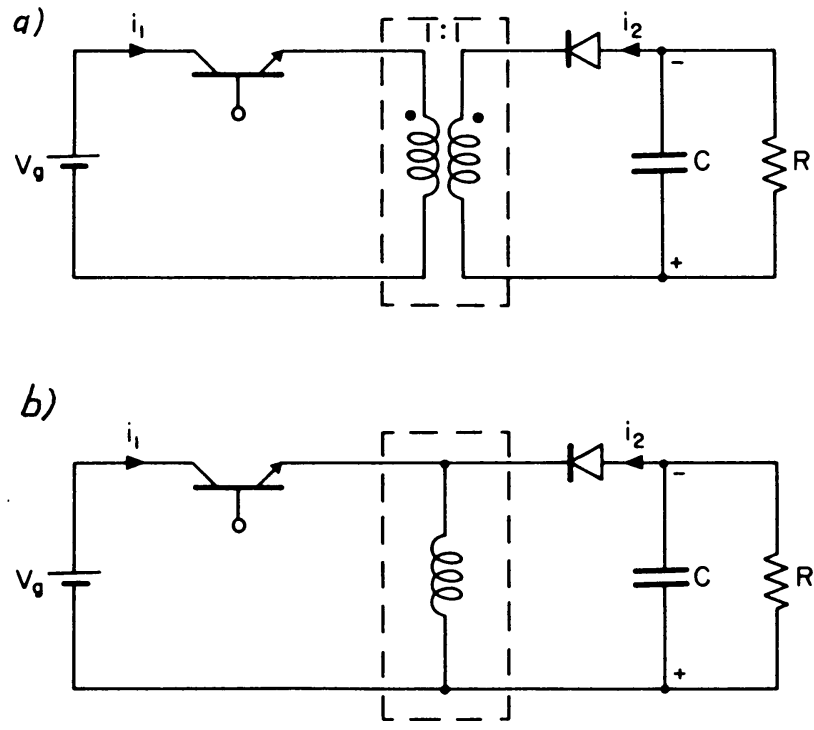

Fig. 15 Transformer-coupled buck-boost $(a \mid$ and its special case--single-inductor buckboost converter (b)
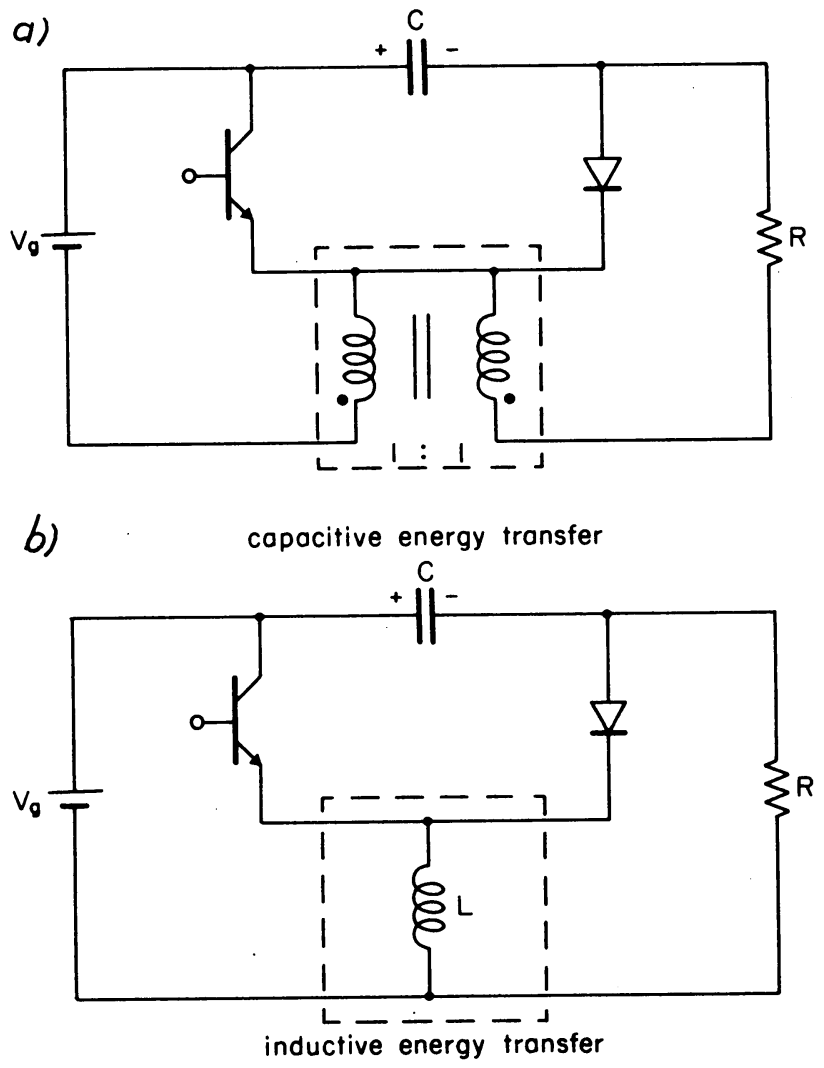

Fig. 16 Coupled-inductor Cuk converter $(a)$ and its special case--single-inductor ćuk converter (b) 
While in the general case of Fig. 16a, zero current ripple and even negative current ripple [12] was possible at either input or output side by turns ratio adjustment, that is not possible for the single-inductor Cuk converter (Fig. 16b) owing to the loss of one degree of freedom--the turns ratio. The current ripples in Fig. $16 \mathrm{~b}$ at input and output then divide inversely to their source and load impedances at the switching frequency. Since the load can often have a significant capacitive part, it could result in a relatively uncontrolled current ripple division between the input and output side. This (Fig. 16) and some other practical aspects of the coupledinductor implementation, which do not require turns ratio adjustment, are dealt with in detail in [14].

The converter in Fig. 16b is now in a form directly applicable for duality transformation, which follows along the same lines as before (Fig. 17). However, from Fig. 17 it is apparent that the duality transformation results in a converter of the same topology. Hence, an interesting result is obtained--the single-inductor Cuk converter is dual to itself, that is its topology is invariant under the duality trans formation. This should come as no surprise, however, since the original capacitive energy transfer is mapped by the duality transformation into an inductive one, and original inductive energy transfer into a capacitive one, thus leading to the same invariant topology. It is also interesting to note that the two switched networks of Fig. $17 \mathrm{~b}$ have the same configurational characteristics of the two switched networks of the basic converter configuration (Fig. 7b). The only difference is that the role of the separate input and output inductances of Fig. $7 \mathrm{~b}$ is now played by a single inductance (which, of course, has to carry the sum of the input and output dc currents). This viewpoint becomes eyen more evident when the singleinductor version is viewed as being directly generated from the basic Cuk converter topology, as illustrated in Fig. 18. As shown in [11], the voltsec balance on the inductors leads to their rectangular voltage waveforms and $1: 1$ relationship (Fig. 18a), provided the capacitance voltage is relatively constant (negligible ripple). In the layout of Fig. 18b, input and output inductors have a common junction. Thus, although the potentials on the other ends of inductors (points $A$ and $B$ in Fig. 18b) vary between the input dc voltage $\mathrm{V}_{g}$ and the output dc voltage $-\mathrm{V}$, the change is ${ }^{g}$ simultaneous, such that both points $A$ $\& B$ are at equal potential (either $V_{\text {or }}-V$ ) throughout the whole switching intergal. Thus points $A$ and $B$ can be connected (dotted line in Fig. 18b) to yield a single-inductor Cuk converter (Fig. 18c) with effective inductance $\mathrm{L}_{e}=\mathrm{L}_{1}|| \mathrm{L}_{2}$. This is an interesting result, since an earlier investigation [16] concluded that the discontinwous inductor current mode in the basic converter (Fig. 18b) is determined by the sum of input and output currents $\left(i_{1}+i_{2}\right)$ going to zero and is governed by the dimensionless parameter $\mathrm{K}_{\mathrm{C}}=2 \mathrm{~L}_{\mathrm{f}} / \mathrm{R}$ where $\mathrm{L}_{\mathrm{e}}=\mathrm{L}_{1} / \mid \mathrm{L}_{2}$. The physical explanation of such a result becomes now especially transparent in Fig. 18c. From its generation, either as in Fig. 16 or in Fig. 18 it is
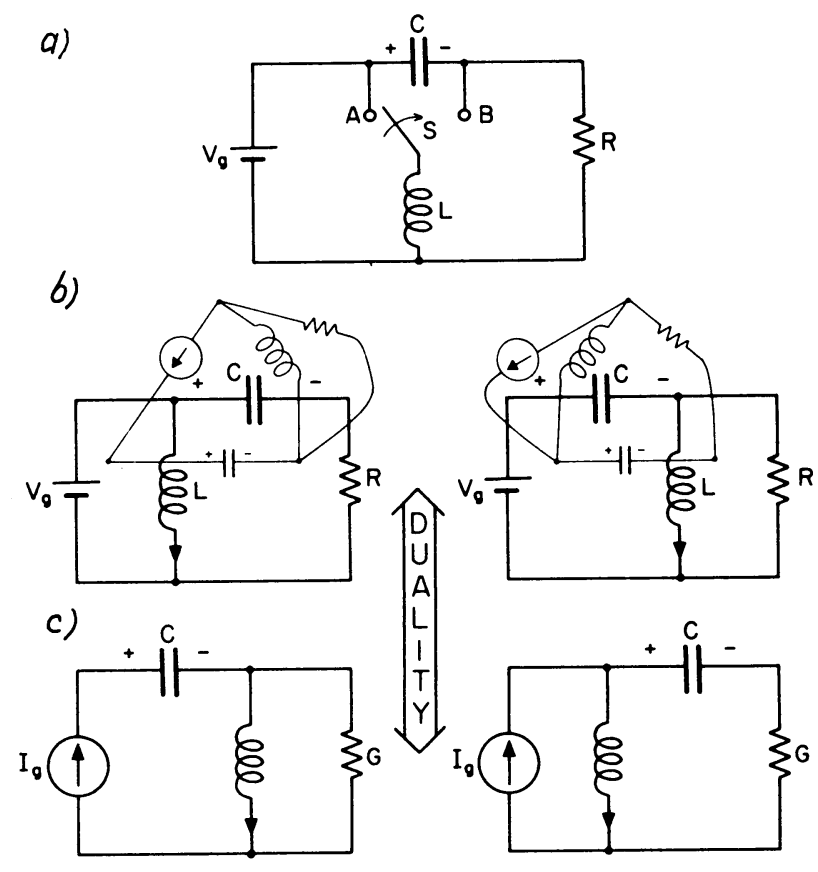

d)

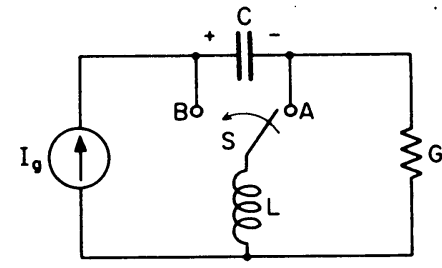

Fig. 17 Single-inductor Ćuk converter is invariant under the duality trans formations

also afparent that the single-inductor Cuk converter maintains the outstanding feature of the basic configurations, that is nonpulsating input and output currents $i_{1}$ and $i_{2}$ (Fig. 8b), which is in sharp contrast with the corresponding pulsating currents in the conventional buck-boost converters (Fig. 15).

Although the special cases are important in themselves, it should be emphasized that the coupled-inductor Cuk converter is the most general case which, except for the dc isolated version (Fig. 13), encompasses all other special cases:

a) for zero coupling coefficient $(k=0)$ it reduces to the basic Ćuk converter (Fig. 8a), which in turn can be reduced to a singleinductor Ćuk converter

b) for perfect-transformer mode1 (coupled-inductors) and $1: 1$ turns ratio it reduces also to a single-inductor Cuk converter.

These special cases are easy to see and follow directly from the general result in a straightforward way. The opposite approach to arrive at the general result from these special cases is a tremendously more difficult process, which usually calls for a key quantum jump, which suddenly puts everything nicely together. Here that key step is the coupling of inductors [11], which allows remaining correlations to be easily established via a deductive approach. 
a)
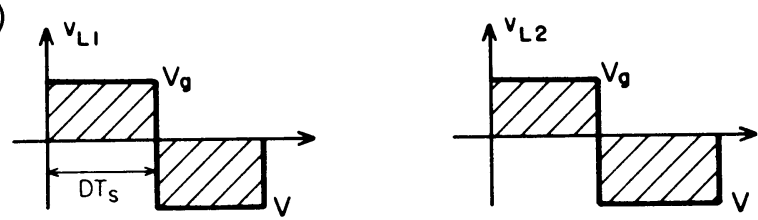

b)
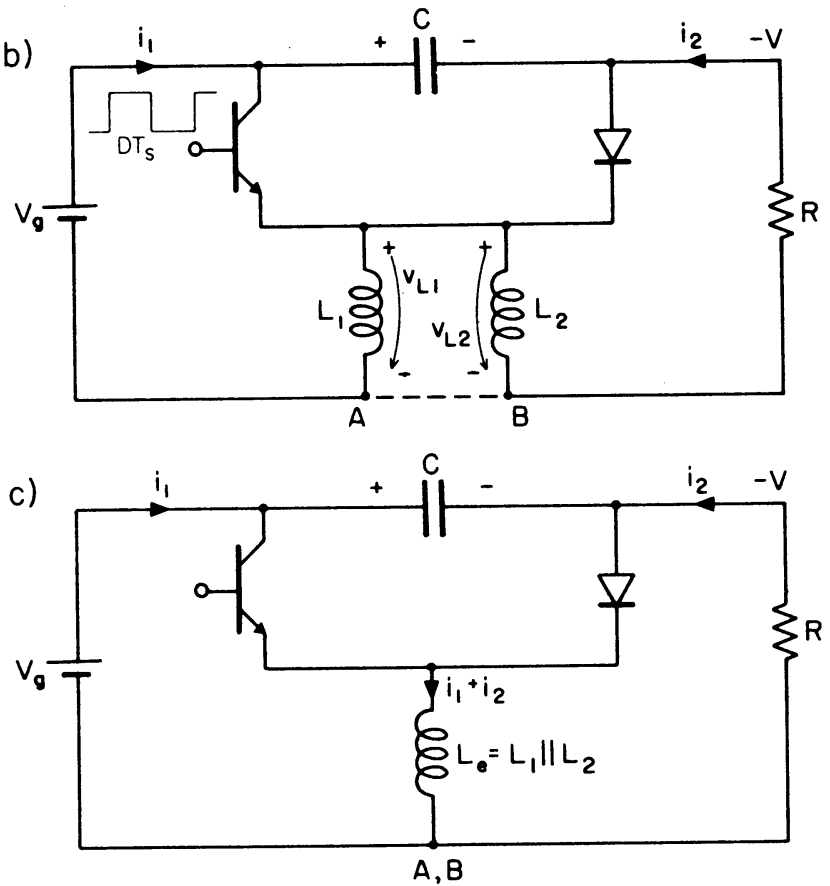

can be made, which further emphasizes the importance of the optimum interconnection topology. It has already been observed (see Fig. 22 in [11]) that the coupled-inductor Cuk converter can be obtained from the conventional buck-boost by change of position of only one component--the output capacitance, and substituting it for the energy transfer capacitance in the coupled-inductor Cuk converter. This viewpoint is again illustrated in Fig. 19 for both transformer-coupled and single-inductor versions of the two converter families. Although in either case it involves the change of position of the same component (capacitance), that change produces a fundamental difference in the performance and operation of the two converter types [11]. In its dotted line position in Fig. 19, the capacitance effectively takes part in energy (and power) transfer, helping to smooth out the energy transfer from input to output, while in the conventional buck-boost (heavy line in Fig. 19) it merely serves to redistribute the power transferred by the only available inductive energy transfer. The substantial differences in efficiency of operation and switching ripple performance $[2,3]$ are directly related to nonpulsating currents in one family versus the pulsating currents in the other family.

An important general conclusion regarding converter topologies, substantiated by some earlier comparisons $[3,10]$, can now be made:

Different converter topological interconnections of the same components can lead to markedly different results in terms of efficiency, switching ripple, dynamic response and overald performance.
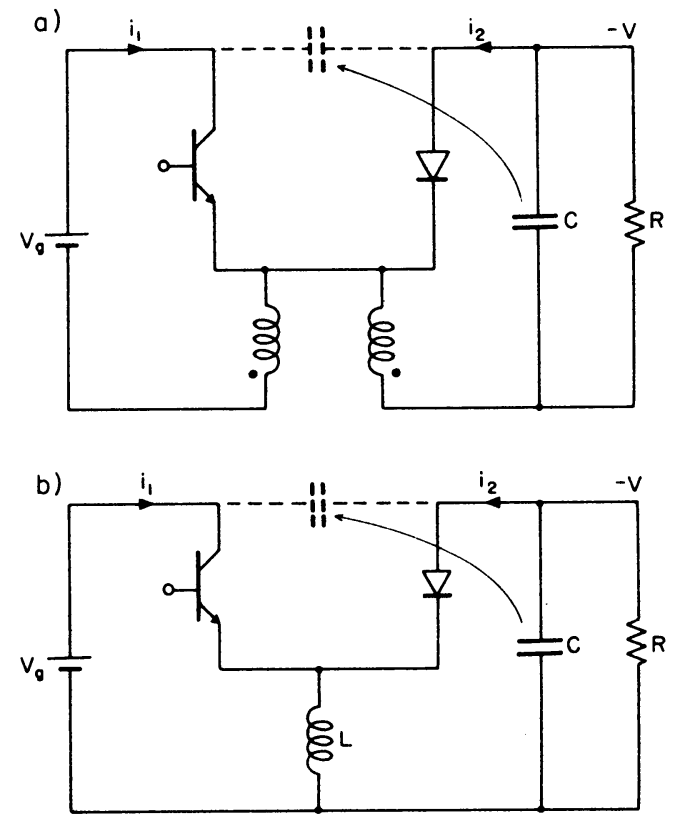

Fig. 19 Change of one component position loutput capacitancel in the buck-boost converter leads to Cuk converters and significant performance improvement 
Let us finally clarify some misconceptions which may arise with regard to Fig. 19 if the role of capacitance in the dotted line position is not understood properly. An oversimplified argument which can easily lead to misinterpretation of its operation is to regard the Cuk converters in Fig. 19 as obtained from the conventional buck-boost converter by addition of an extra capacitance between the input and output ports. Suppose that the buck-boost was in a black box and capacitance added externa11y between the input and output ports. The logical consequence is that the extra capacitance would charge to the potential difference between the input and output dc voltages of the original buck-boost converter and then cease conducting current (no current in capacitance any more). However, in the Cuk converter this does not happen since the capacitance is now an integral part of the switching process and in fact it is the original energy transfer capacitance of the basic Cuk converter. Hence, it will alternately charge from the input source (inteval $\mathrm{D}^{\prime} \mathrm{T}$ ) and discharge to the load (interval DT ${ }_{S}$ ), thus resulting in a large rectangular current ripple in the capacitor (see Fig. 20 and discussion of charge balance criteria in Section 5). This once again demonstrates that the placement of the capacitance in the dotted line position in Fig. 19 leads to a fundamental change of operation and is in fact a crucial difference between the two types of converters.

So far we have made a major step in establishing duality relationships among a variety of switching converter topologies. Let us now see what other benefits can be derived from these duality relationships.

\section{CONTINUOUS CONDUCTION MODE AND DUALITY}

Let us now examine more closely the duality relationship between the conventional buck-boost converter and the Cuk converter founded in Section 3. As seen in Fig. 20, in the conventional buckboost converter, all the elements (current source, storage elements and load) are "connected" in parallel while switch $S$ acts as a series element. In the dual converter of Fig. 20b, the corresponding dual elements are connected in series, while the switch $S$ acts as a parallel element with positions A being corresponding dual positions. In both converters position A corresponds to energy accumulation, in Fig. 20a in the inductor $\mathrm{L}$ via electromagnetic field, and in Fig. 20b in the electric field via electric charge. However, owing to the practical bipolar transistor, diode realization of switch $S$ in the Cuk converter, (Fig. $8 \mathrm{~b})$, the duty ratio (on-time of the transistor switch) is referred to the point $B$ in Fig. $20 \mathrm{~b}$. Thus, as shown before (11), the duality relationships are slightly modified: where in any statement or expression $D$ appears in the conventional converter, it should be replaced with $D^{\prime}=1-D$ in the Ćuk converter and vice versa. Apart from this minor modification due to the switch duty ratio definition, complete duality relationships exist.

\subsection{Charge Balance as a Dual to Field Balance}

Let us first recall a simple method for steady-state (dc conditions) determination in the buck-boost converter (Fig. 20a) and any other converter based on inductive energy transfer by use of the so-called volt-sec balance on inductors:

$$
\int_{0}^{\mathrm{T}} \mathrm{s} \quad \mathrm{v}_{\mathrm{L}} \mathrm{dt}=\int_{0}^{\mathrm{T}} \mathrm{Ldi}_{\mathrm{L}}=\phi\left(\mathrm{T}_{\mathrm{s}}\right)-\phi(0)=0
$$

that is, the net field change after a complete cycle is zero (no "accumulation" of the field). For the converter in Fig. 20a, and with assumption of constant voltages $\mathrm{V}_{1}$ and $\mathrm{V}_{2}\left(\mathrm{C}_{1} \& \mathrm{C}_{2}\right.$ large enough), volt-sec balance (12) yields

$$
\mathrm{v}_{1} \mathrm{DT}_{\mathrm{s}}=\mathrm{V}_{2} \mathrm{D}^{\prime} \mathrm{T}_{\mathrm{s}} \rightrightarrows \frac{\mathrm{v}_{2}}{\mathrm{v}_{1}}=\frac{\mathrm{D}}{\overline{\mathrm{D}}} \text {, }
$$

From the duality principle we now expect a dual amp-sec balance on capacitors to exist in the switching converters based on capacitive energy transfer. Indeed, a dual relation to (12), the amp-sec (charge) balance on capacitors becomes

$$
\int_{0}^{\mathrm{T}} \mathrm{s}_{\mathrm{i}} \mathrm{dt}=\int_{0}^{\mathrm{T}} \int^{\mathrm{s}} \mathrm{Cdv_{c }}=\mathrm{q}\left(\mathrm{T}_{\mathrm{s}}\right)-\mathrm{q}(0)=0
$$

That is, the net contribution of charge over a complete cycle is zero (no accumulation of charge) This latter criterion of charge balance may even be easier to comprehend physically. The charge stored on capacitance during one position of the switch must be equal to the charge released to the load during the complementary interval. Hence, for the converter in Fig. 20b, and from its rectangular capacitor current waveform, the criterion (14) yields

$$
I_{2} D_{s}=I_{1} D^{\prime} T_{s} \Rightarrow \frac{I_{2}}{I_{1}}=\frac{D^{\prime}}{D}
$$

Again the switch drive definition is responsible for the reversal of the slopes of capacitance voltage in Fig. 20b, in comparison with their dual counterpart--the triangular inductor current waveform of Fig. 20a. Note also the rectangular inductor voltage waveform (Fig. 20a) and dual rectangular capacitor current waveform (Fig. 20b) with the shaded areas pictorially representing volt-sec and amp-sec balance respectively.

The two dc gains (13) and (15) can actually be obtained even directly from each other by use of the duality principle as shown earlier in (10) and (11). However, duality principle is even more general in that it allows for all properties of a network to be concluded from the properties of its dual network. Let us then see how it relates their dynamic (ac small-signal) properties. 


\section{dual steady-state criteria}

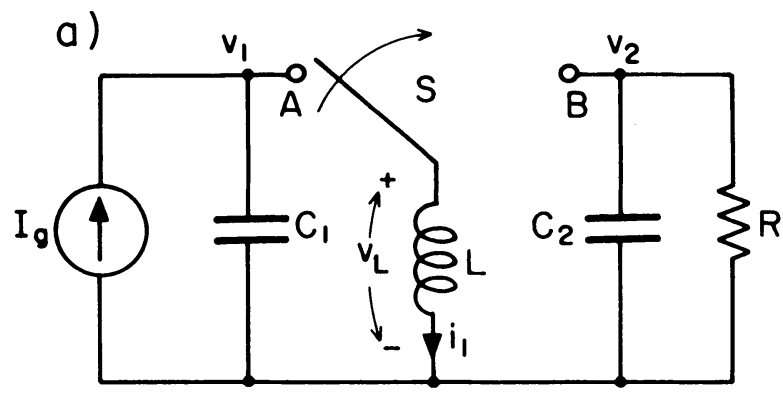

field balance

volt-sec balance on inductor
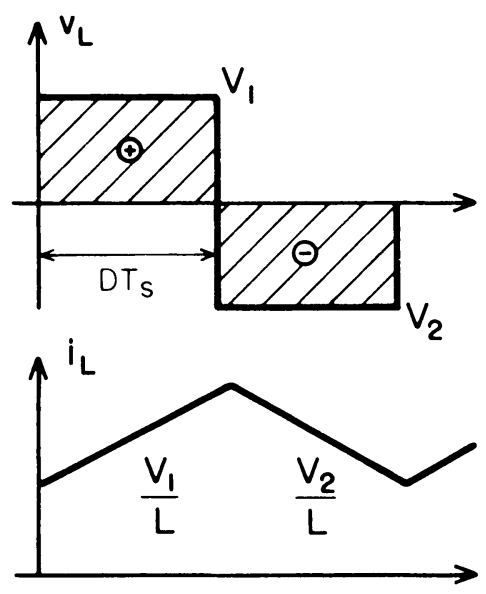

$$
\begin{aligned}
\int v_{L} d t=0 \Rightarrow & V_{2} D^{\prime} T_{S}=V_{1} D T_{S} \\
& \frac{V_{2}}{V_{1}}=\frac{D}{D^{\prime}}
\end{aligned}
$$

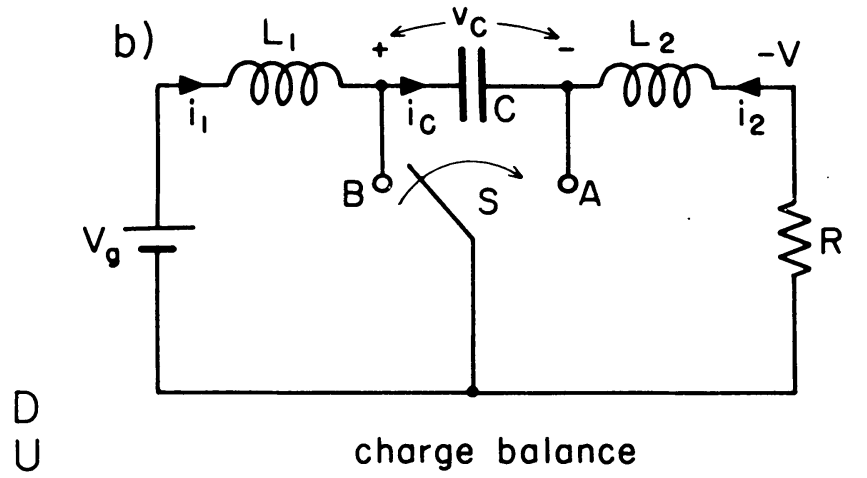

A

amp-sec balance on capacitor

$L$

Fig. 20 Duality of two steady-state criteria: field balance on inductors $(a)$ and charge balance on capacitors (b)

\subsection{Dynamic (Ac Small-Signal) Properties of Switching Converters and Duality}

The previous work $[17,3,18,19]$ in modelling and analysis has culminated in the establishment of a fixed topology, canonical circuit model which properly models dynamic (ac small-signal) properties of any switching converter in the continuous conduction mode. It is a linear equivalent circuit model, linearized around a steady-state operating point. Although it is of a fixed topological structure its element values differ for different converter configurations. For example, the element values and canonical model for the buck-boost current converter of Fig. 20a are showr in Fig. 21a.
We could now proceed to use the state-space averaging technique $[3,18,19]$ and arrive at the canonical circuit model of the cuk converter in Fig. 20b. However, by use of the powerful duality principle its equivalent circuit model can be obtained directly by finding a dual network of the equivalent circuit model for the buck-boost converter.

Several key steps in that dual transformation are illustrated in Fig. 21. Although a presence of an ideal ac and dc transformer in the canonical mode1 (Fig. 21a) may at first seem an obstacle for duality transformation, it is easily removed by modelling ideal transformer with the controlled generators as in Fig. 21b. The standard algorithm then leads to a dual network in Fig. 21c in which 

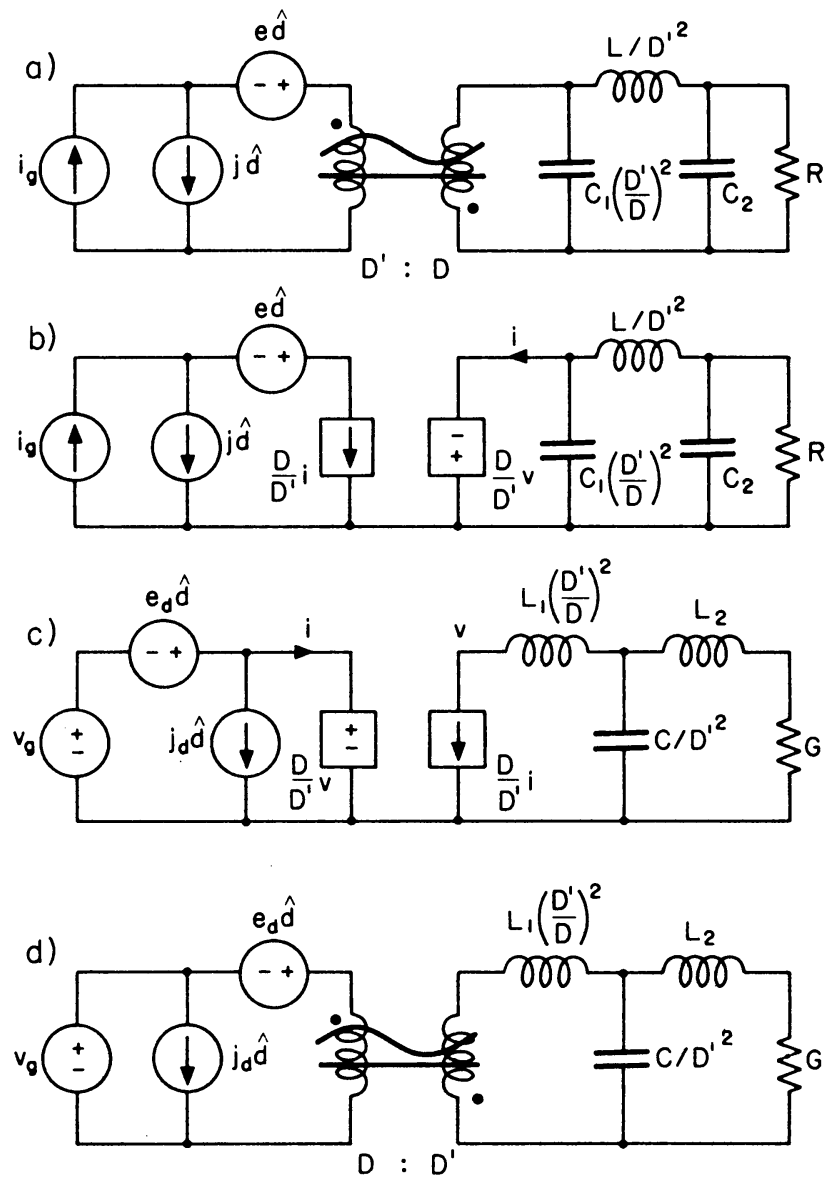

Fig. 21 Duality transformation of a canonical circuit model (a) leads to the same topological structure (d)

generator $e_{j}(s)$ and $j_{d}(s)$ expressions are obtained as dual to $j(s)$ and $e(s)$ generator expressions in the starting model (Fig. 21a). Namely, the paralcel current generator $j(s) \hat{d}$ of $F i g .21 b$, becomes a series voltage generator $e(s) d$ of $F i g .21 c$, while a series voltage generator $e(s) \hat{d}$ of Fig. $21 \mathrm{~b}$, becomes a parallel current generator $j_{d}(s) \hat{d}$ of Fig. 21c. Their dual quantitative expressions obtained by duality replacements (2) and (3) are

$$
\begin{aligned}
& e(s)=\frac{V_{2}}{D^{2}}\left(1-s \frac{D}{D^{\prime 2}} \frac{L}{R}\right) \quad \begin{array}{l}
D \\
U \\
A
\end{array} \\
& j_{d}(s)=\frac{I_{2}}{D^{2}}\left(1-s \frac{D}{D^{\prime 2}} \frac{C}{G}\right) \\
& j(s)=\frac{I_{2}}{D^{\prime^{2}}}\left(1-s C_{1} R \frac{D^{\prime}}{D}+s^{2} \frac{L C_{1}}{D}\right) \frac{D}{U} \\
& e_{d}(s)=\frac{V_{2}}{D^{\prime 2}}\left(1-s L_{1} G-D^{\prime}{ }^{2}+s^{2} \frac{L_{1} C}{D}\right)^{L} s
\end{aligned}
$$

Note also that the dependent voltage generator $\frac{\mathrm{D}}{\mathrm{D}^{\prime}} \mathrm{v}$ of Fig. 21b, became a dependent current generator $\frac{D}{D}, i$ of Fig. 21c, and analogously for other dependent generators. Finally in Fig. 21d an ideal $D: D^{\prime}$ transformer is recovered which corresponds to the original D':D transformer of Fig. 2la. Note that the duty ratio dependent sources can be interchanged in Fig. 21c to result in the same input structure as in Fig. 21a. Finally, the original $\pi$ low-pass filter structure (Fig. 21a), has been transformed into a $\mathrm{T}$ low-pass filter structure (Fig. 21d). An interesting result is therefore obtained.

The dual network of the canonical circuit model is the network of the same fixed topological form, namely duty ratio dependent generators (control), followed by a transformer (basic dc-todc conversion) and loaded by an effective low-pass filter structure. Thus, the canonical circuit model for continuous conduction mode has the special form which is invariant (having the same qualitative structure) under the duality transfornation. However, this should have been expected, since based on previous results $[17,18,19]$ both converters result in the canonical circuit mode1, that model should have a structure which is dual to itself.

To complete duality relationships for their models in continuous conduction mode, the substitution $\mathrm{D} \leftrightarrow \mathrm{D}^{\prime}$ is introduced (different duty ratio definitions in the two converters) and Fig. 22 obtained in which the generators $e_{c}(s)$ and $j_{c}(s)$ are obtained from (16) and (17) as ${ }^{c}$

$$
\begin{aligned}
& e_{c}(s)=\frac{V_{2}}{D^{2}}\left[1-s \frac{L_{1}}{R} \frac{D^{2}}{D^{\prime}}+s^{2} \frac{L_{1} C}{D^{\prime}}\right] \\
& j_{C}(s)=\frac{I_{2}}{D^{\prime^{2}}}\left[1-s \frac{D^{\prime}}{D^{2}} C R\right]
\end{aligned}
$$

The obtained generators (18) are the same as previously obtained independently $[2,3]$, thus once again verifying the complete duality relationships which now include their small-signal equivalent circuit models. Therefore, the knowledge of ynamic properties of only one of the converters is sufficient to have a complete knowledge (qualitatively as well as quantitatively) of the behaviour of its dual converter in the continuous conduction mode.

\section{DISCOYTINUOUS CONDUCTION MODE AND DUALITY}

When the ideal switch in the juck-hoost con-verter (Fig. 22a) is implemented by a bipolar transistor, diode combination, another mode of operation-the discontinuous inductor current mode (until now also called discontinuous conduction mode) is obtained. It comes directly as a consequence of an unidirectional current carrying capability of the switch implementation, and more specifically due to the diode unidirectional characteristic. This immediately rises a question: 
duality in continuous conduction mode (dynamic)
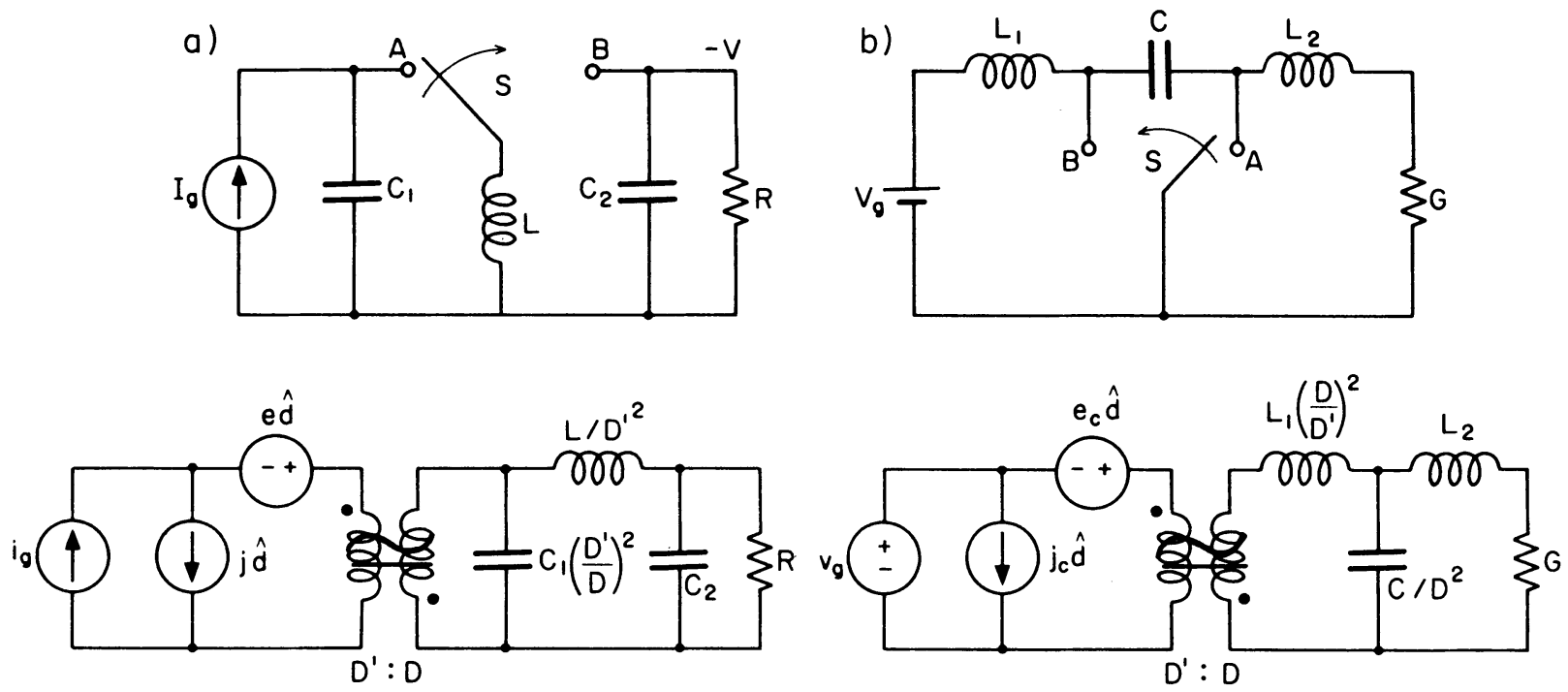

Fig. 22 Duality of the equivalent circuit models in continuous conduction mode

Could an analogous, the discontinuous capacitance voltage mode exist in the dual converter, when its switch is implemented by unidirectional voitage carrying devices?

The answer is affirmative and comes as a direct consequence of the application of duality principle.

\subsection{A New Discontinuous Capacitance Voltage Mode of Switching Conyerter Operation}

To get better understanding of this new mode of converter operation let us first briefly review with the help of Fig. 23a the discontinuous inductor current mode of operation in the buckboost converter. For simplicity we assume that $\mathrm{C}_{1}$ and $\mathrm{C}_{2}$ are sufficiently large to result in essentially dc voltages $\mathrm{V}_{1}$ and $\mathrm{V}_{2}$. Consider now its operation when the inductance value is gradually decreased. For a sufficiently small inductance value, the inductor current reduces to zero $\left(i_{1}=0\right)$ even before the end of second interval D'T. Since inductor current was originally keeping the diode on, the diode turns off and a third switched network is obtained for interval $\mathrm{D}_{3} \mathrm{~T}$ for which both transistor and diode are off (see Fig. 23a). This is in addition to the two switched networks (Fig. 7b) appearing in the continuous conduction mode (transistor on, diode off and vice versa).

Consider now the analogous situation in the converter of Fig. 23b. Again, for simplicity of discussion, the two inductances $\mathrm{L}_{1}$ and $\mathrm{L}_{2}$ are assumed large enough to effectivety result in practically dc currents $I_{1}$ and $I_{2}$. Suppose that we are now reducing the size of the energy transferring capacitance $C$. For a sufficiently small capacitance value, the capacitance is fully discharged even before the first switched interval
DT (transistor on) has expired as shown in Fig. $23 \mathrm{~b}$, and its voltage is reduced to zero $\left(\mathrm{v}_{\mathrm{f}}=0\right)$. However, since the capacitor voltage was originally keeping the diode reverse biased and of $f$ during interval DT ${ }_{s}$, now that $v_{c}=0$ there is nothing to keep the diode from conducting. Namely, the diode becomes forward biased to keep the output inductor current $i_{2}$ flowing. Thus a third switched network is generated for interval $\mathrm{D}_{3} \mathrm{~T} \equiv\left(\mathrm{D}-\mathrm{D}_{2}\right) \mathrm{T}_{\mathrm{s}}$, for which bcth transistor and diode are on (Fig. $23 \mathrm{~b})$. This is in addition to the two switched networks appearing in its continuous conduction mode (Fig. 7c) (transistor on, diode off and vice versa).

It does not take long to see that the additional third switched networks are actually dual to each other. The "open" position of switch in Fig. 23a, corresponds to a "shorted" switch position in its dual network in Fig. 23b. The duality relationships for other two switched networks have been established earlier (Fig. 7). Therefore, an important conclusion can be made:

Duality relationship in switching converters can be extended to even include their discontinuous conduction mode of operation.

This result becomes even more transparent if the discontinuous conduction mode is considered as an appropriate restriction on some internal variables (inductor currents and capacitor voltages) which are in turn consequences of the unidirectional properties of the switch implementations. For example, in Fig. 10 a more general method for dual network construction was presented which uses controlled source for the switch representations. If, for example, in Fig. 10a in addition to the switching parameter $\alpha \epsilon[1,0]$ a restriction on an internal parameter, such as inductor current is imposed as $i=0$, the third switched network of 
duality in discontinuous conduction mode (steady state)
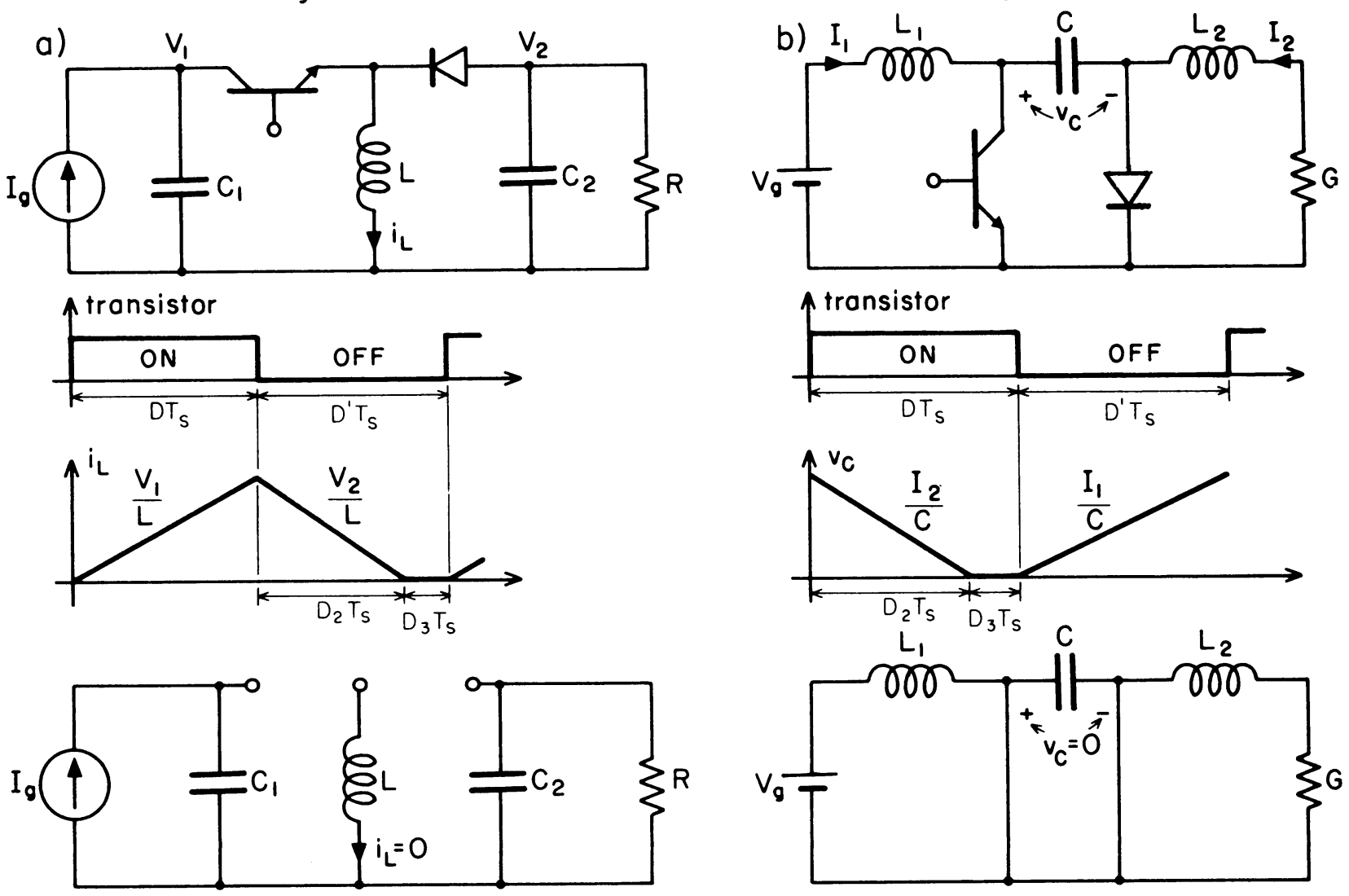

$K_{L} \triangleq \frac{2 L}{R}$ fs

$K_{C} \triangleq K_{L}(L \rightarrow C, R \rightarrow G)=\frac{2 C}{G} f s=2 R C f s$

$\frac{I_{2}}{I_{g}} \triangleq \frac{\sqrt{K_{L}}}{D}$

$\frac{V_{2}}{V_{g}}=\frac{I_{2}}{I_{g}}\left(\begin{array}{l}I_{2} \rightarrow V_{2}, K_{L} \rightarrow K_{C} \\ I_{g} \rightarrow V_{g}, D \rightarrow D^{\prime}\end{array}\right)=\frac{\sqrt{K_{C}}}{D^{\prime}}$

discontinuous inductor current

$$
\mathrm{K}_{\mathrm{L}}<\mathrm{D}^{\prime 2}
$$

\section{discontinuous capacitor voltage

$$
\mathrm{K}_{\mathrm{c}}<\mathrm{D}^{2}
$$

Fig. 23 Duality between the discontinuous inductor current mode $(a)$ and the new discontinuous capacitance voltage mode of converter operation (b)

Fig. 23a is obtained, since current controlied source $(1-\alpha) i$ became zero even for $\alpha=0$ (corresponds to diode opening in discontinuous inductor current mode). However, when a corresponding dual restriction $\mathrm{v}=0$ is imposed on the converter of Fig. 10b, the third switched network for the Cuk converter (Fig. 23b) is obtained, since voltage controlled source $(1-\alpha) v$ became zero even for $\alpha=0$. In fact, the controlled sources representation of the switches as in Fig. 10, describes both converters completely in continuous as well as discontinuous conduction mode of operation.

\subsection{Steady State (dc) Results in Discontinuous Capacitance Voltage Mode}

The duality principle has led us so far to uncover qualitatively a completely new mode of switching converter operation--the discontinuous capacitance voltage mode. Furthermore, it was verified that a complete duality holds between switching converters not only in their continuous conduction mode, but even in their corresponding discontinuous conduction modes of operation.

We may again invoke the powerful duality principle and obtain even the quantitative results for this new discontinuous capacitance voltage mode directly on the basis of the results for its dual counterpart, the conventional buck-boost converter operated in discontinuous inductor current mode.

We now recall [15] that a single dimensionless parameter $K_{L}$ uniquely combined all the parameters responsible for discontinuous inductor current operation (inductance $\mathrm{L}$, load $\mathrm{R}$, period $\mathrm{T}_{\mathrm{s}}$ ), and played a key role in actual quantitative determin- 
ation (such as voltage gain, second interval $\mathrm{D}_{2} \mathrm{~T}_{\mathrm{s}}$, etc.). The dimensionless parameter $\mathrm{K}_{\mathrm{L}}$ was defined in [15] as:

$$
\mathrm{K}_{\mathrm{L}}=\frac{2 \mathrm{~L}}{\mathrm{R}} \mathrm{f}_{\mathrm{s}}
$$

The single dimensionless parameter $\mathrm{K}$ which will govern the behaviour of the converter in Fig. $23 \mathrm{~b}$ in the discontinuous capacitance voltage mode is the dual of $K_{L}$ and easily obtained from (19) as

$$
\mathrm{K}_{\mathrm{C}}=\mathrm{K}_{\mathrm{L}}(\mathrm{L} \rightarrow \mathrm{C}, \mathrm{R} \rightarrow \mathrm{G})=\frac{2 \mathrm{C}}{\mathrm{G}} \mathrm{f}_{\mathrm{S}}
$$

However, since $R \leftrightarrow G$ correspondence really means $G=1 / R$ in terms of converter resistance,

(20) becomes

$$
\mathrm{K}_{\mathrm{c}}=2 \mathrm{RCF}_{\mathrm{s}}
$$

The region of the discontinuous inductor current mode of buck-boost (Fig. 23a) obtained in [15] as

$$
K_{L}<D^{\prime 2}
$$

is mapped by the duality transformation into a corresponding region for the discontinuous capacitance voltage mode of the converter in Fig. $23 \mathrm{~b}$ as

$$
\mathrm{K}_{\mathrm{c}}<\mathrm{D}^{2}
$$

where also the substitution $D \leftrightarrow D^{\prime}$ is used because of the difference in the duty ratio $D$ reference definition in the two converters.

Finally, from the dc current gain in the buckboost converter in discontinuous inductor current mode, [15]

$$
\frac{I_{2}}{I_{g}}=\frac{\sqrt{K_{L}}}{D}
$$

the dc voltage gain of the Cuk converter in the discontinuous capacitance voltage mode becomes

$$
\frac{V_{2}}{V_{g}}=\frac{I_{2}}{I_{g}}\left(\begin{array}{l}
I_{2} \rightarrow V_{2}, K_{L} \rightarrow K_{c} \\
I_{g} \rightarrow V_{g}, D \rightarrow D^{\prime}
\end{array}\right)=\frac{\sqrt{K_{c}}}{D^{\prime}}
$$

where $K_{c}$ is as defined before in (21).

Thus, all the steady-state results for one converter are obtained directly from the corresponding results for its dual counterpart. A1though these results for discontinuous capacitance voltage mode could be independently verified and obtained by application of the general state-space averaging method $[2,20]$, let us verify some of these results by simpler means.

For example, the boundary between the continuous and discontinuous capacitance voltage mode is easily seen from Fig. $23 \mathrm{~b}$ to be when

$$
\mathrm{v}_{\mathrm{c}}=\frac{1}{2} \Delta \mathrm{v}_{\mathrm{c}}
$$

where $V_{\text {c }}$ is average capacitance voltage and $\Delta v$ maximum triangular ripple with $\mathrm{I}_{2} / \mathrm{C}$ slope for interval $\mathrm{DT}_{\mathrm{s}} \cdot$ Therefore (26) leads to

$$
\frac{\mathrm{V}}{\mathrm{D}}=\frac{1}{2} \frac{\mathrm{V}}{\mathrm{R}} \frac{\mathrm{DT}}{\mathrm{C}}
$$

which rearranged results in boundary region definition

$$
2 \operatorname{RCf}_{s}=D^{2}
$$

This is, of course, the same result as obtained earlier in (23). Another interpretation of the results in (26) and (28) gives the relative ripple voltage present on the energy transferring capacitance as

$$
\frac{\Delta \mathrm{v}_{\mathrm{c}}}{\mathrm{V}_{\mathrm{c}}}=\frac{\mathrm{D}^{2}}{\mathrm{RCf}}
$$

which is very useful for practical implementations.

Very often it is important to know simple criteria which will insure the operation in the continuous conduction mode, regardless of the operating point change (duty ratio $\mathrm{D}$, that is). From (22) the buck-boost (Fig. 23a) will always operate in continuous inductor current mode when

$$
\frac{2 L}{R} f_{S}>1
$$

while its dual counterpart (Fig. 23b) operates always in continuous capacitance voltage mode when

$$
2 \operatorname{RCf}_{\mathrm{s}}>1
$$

By comparison of (30) and (31) the qualitatively different way of entering discontinuous conduction mode through load $\mathrm{R}$ changes is observed. The discontinuous inductor current mode is obtained by violating (30) and by increasing load resistance value. In fact, to maintain buck-boost converter in continuous inductor current mode

$$
\mathrm{R}<\mathrm{R}_{\max }=2 \mathrm{Lf}_{\mathrm{s}}
$$

while its dual counterpart will be maintained in continuous capacitance voltage mode when

$$
\mathrm{R}>\mathrm{R}_{\text {min }}=\frac{1}{2 \mathrm{Cf}_{\mathrm{s}}}
$$

As a numerical example, for $\mathrm{L}=50 \mu \mathrm{H}, \mathrm{C}=50 \mu \mathrm{F}$, $\mathrm{f}_{\mathrm{s}}=100 \mathrm{kHz}, \mathrm{R}_{\max }=10 \Omega$ and $\mathrm{R}_{\text {min }}=0.1 \Omega$.

It is, therefore, now apparent that the terms sometimes used to designate the continuous conduction mode as a "heavy" mode (due to heavy loading, high current, small resistance $R$ ) and 
discontinuous conduction mode as a " 1 ight" mode (light loading, small average current, high resistance R) became completely inappropriate, when this new phenomenon of discontinuous capacitance voltage mode is considered. It is, then, suggested that the terms "discontinuous inductor current" (DIC) mode and "discontinuous capacitance voltage" (DCV) mode be used, since they define the primary causes of such behaviour, rather than by describing them through only one of the means of arriving at them (change of load $R$ ), and neglecting other equally important parameters $\mathrm{L}, \mathrm{C}$ and $\mathrm{f}_{\mathrm{s}}$.

It should be emphasized that this qualitatively new feature of discontinuous capacitance voltage mode is also present in the single-inductor Cuk converter (Fig. 18b or 19b), since that special case also retains the original capacitive energy transfer feature of the Cuk converter. Furthermore, all the above quantitative results are equally valid for single-inductor version. In fact, the duality relationship between two discontinuous conduction modes applies equally well to other converters with more than a single switch, such as for example, ones shown in Fig. 24.
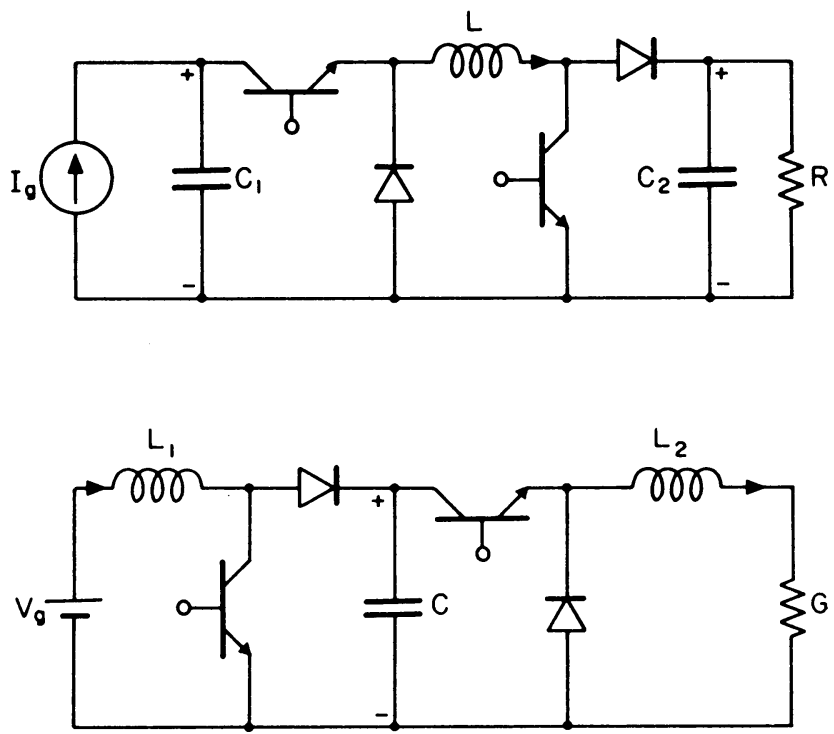

Fig. 24 Another example for duality between the two discontinuous conduction modes

\subsection{Dynamic Response in the Discontinuous Capacitance Voltage Mode}

Although an ac model can be obtained by use of the general state-space averaging technique $[2,20]$ which proceeds analogously to the discontinuous inductor current treatment [20], we will again take a shortcut.

The dynamic (ac small-signal) equivalent circuit model for the voltage driven buck-boost converter (Fig. 1) derived elsewhere $[2,20]$ can be easily updated for the current driven buck-boost as shown in Fig. 25a. Note, that now instead of the external dc voltage gain as a parameter, an external dc current gain $M_{c}=I_{2} / I_{g}$ is used.
The dual equivalent circuit to that of Fig. 25a can now easily be found by use of standard algorithm and substitutions

$$
K_{L} \rightarrow K_{c}, M_{c} \rightarrow M_{v}, R \rightarrow G, I_{2} \rightarrow V_{2}, \hat{v}_{g} \rightarrow \hat{i}_{1}
$$

to result in the equivalent circuit of Fig. 25b. Note also how the voltage controlled current source of Fig. 25a became a current controlled voltage source in dual network of Fig. 25b, while at the same time open circuit (controlling voltage $\hat{v}_{g}$ ) in Fig. 25a became a short circuit (controlling current $\hat{i}_{1}$ ) in Fig. 25b. Another distinguishing feature of the model in Fig. 25b is that the capacitance is effectively removed from the model, and original third order response in continuous conduction mode reduced to a two pole response in the discontinuous capacitance voltage mode such that the two transfer functions of interest are:

$$
\begin{aligned}
& G_{i g}=\frac{\hat{i}_{2}}{\hat{i}_{g}}=M_{C} \frac{1}{\left(1+s C_{1} R M_{c}^{2}\right)\left(1+s C_{2} R / 2\right)} \\
& G_{i d}=\frac{\hat{i}_{2}}{\hat{d}}=M_{c} \frac{I_{2}}{\sqrt{K_{L}}} \frac{1-{s C_{1} R M_{c}}^{2}}{1+s C_{1} R_{c}{ }_{c}^{2}} \frac{1}{1+s C_{2} R / 2}
\end{aligned}
$$

Note that the duty ratio to output current transfer function exhibits the undesirable nonminimum phase response due to the presence of the right-half plane zero. How, then, could one explain an earlier result [20], which showed that the right-half plane zero was indeed removed when buck-boost converter (Fig. 5a) was operated in discontinuous inductor current mode? This is, however, now easy to explain with reference to Fig. 25a. When the buckboost converter in Fig. 25a is driven by the voltage source, it merely replaces the current source in the equivalent circuit model of Fig. 25a. But then the input port of the model does not enter into calculation of the voltage transfer function, since the input duty ratio dependent current generator is effectively shorted with $\hat{v}_{g}=0$, while the capacitance $\mathrm{C}$, and resistance $\mathrm{RM}^{\mathrm{g}}{ }^{2}$ only affect the input impedance calculations. Thus, the voltage gains in that case indeed exhibit a single-pole minimum phase response

$$
\begin{aligned}
& G_{v g}=\frac{\hat{v}_{2}}{\hat{v}_{g}}=\frac{R \hat{i}_{2}}{\hat{v}_{g}}=M_{v} \frac{1}{1+s C_{2} R / 2} \\
& G_{v d}=\frac{\hat{v}_{2}}{\hat{d}}=\frac{R \hat{i}_{2}}{a}=\frac{v_{2}}{\sqrt{K_{L}}} \frac{1}{1+s_{2} R / 2}
\end{aligned}
$$

This, again, stresses the importance of the complete equivalent circuit model which correctly models the converter input properties [19].

Example in Fig. 25 illustrates why the search for the canonical circuit model for discontinuous conduction mode (in analogy with canonical circuit model for continuous conduction mode) would not be fruitful. The "parallel" topology of Fig. 25a 
a)
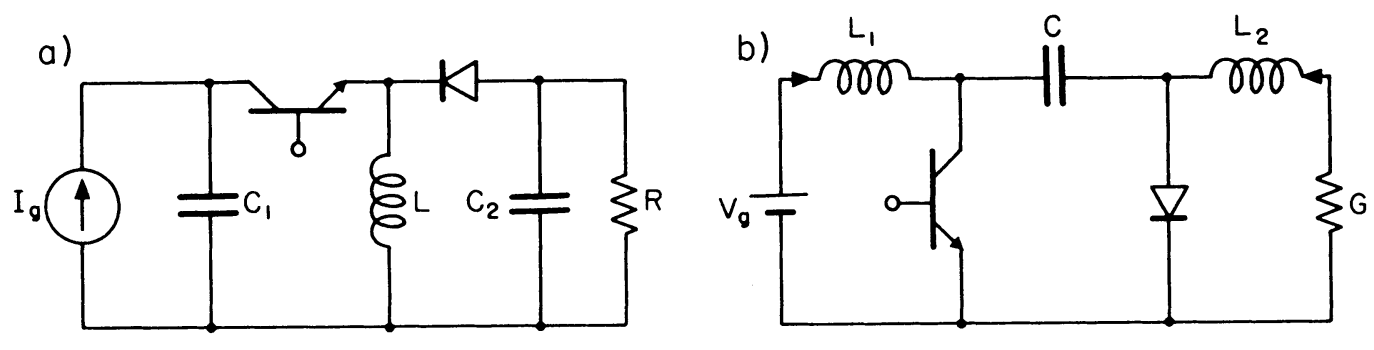

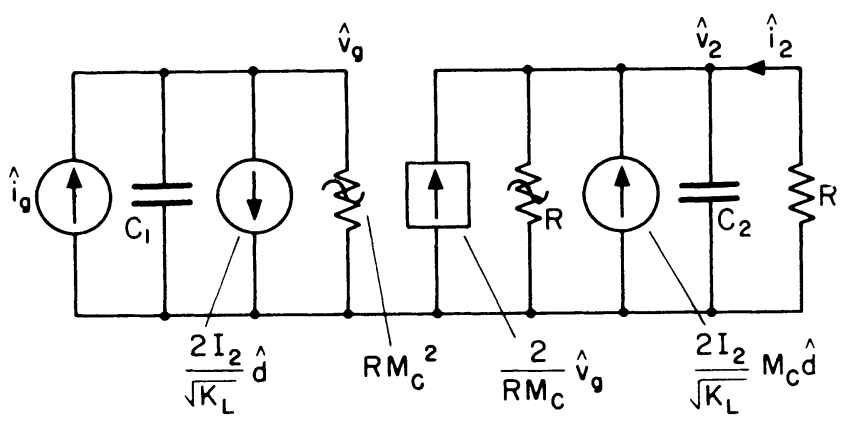

Fig. 25 Duality of equivalent circuit models in discontinuous inductor current mode $(a)$ and discontinuous capacitor voltage mode (b) became a "series" topology of Fig. 25b, hence a fundamental structural change is made. However, the duality relationships allow now that even the ac small signal properties of one converter be completely deduced from the corresponding properties of its dual converter in their respective discontinuous conduction modes.

\section{DUALITY, INVERSION AND SYMMETRY PROPERTIES}

In addition to the duality which is now firmly established as one of the fundamental and most general properties of switching converter structures, there are several other topological properties of particular interest. We will consider here only two--inversion and symmetry.

In the general switching converter representation of Fig. 1a, there is nothing to limit the direction of power flow, since all elements in the box are bilateral. Thus in general, for a given converter configuration, the source and load interchange would result in an equally viable switching converter configuration. Therefore this inversion transformation could be used to generate complementary switching configurations. For example, as shown in [11] the source and load interchange in the buck voltage converter (Fig. 5a) would result in a boost voltage converter (Fig. 6d). Another example using the SEPIC converter (Fig. 12a) is illustrated in Fig. 26. The source and load interchange (shown by dotted lines in Fig. 26) together with the practical bipolar transistor, diode imple- mentation of the original ideal switch appropriate - for the reversed current direction (shown again in dotted lines in Fig. 26) leads to the same topological configuration earlier obtained by use of duality in Fig. 12d. When both transistors and both diodes are present in the converter realization, it possesses the property of bidirectional current and power flow. This is generally the case and as shown in [21] leads to very useful single converter configurations which can be used for both battery charging as well as for supplying the bus voltage from the battery.

While in these examples, the simple inversion tansformation resulted in the same topological configurations as obtained by duality transformation, there are many other configurations, where only duality as a more general tool results in new and viable switching converter configurations, whereas the inversion becomes superficial. For example, symmetry is the topological property in which source and load interchange results in the same configuration. Hence symmetrical switching structures are then invariant under the inversion transformation. The duality transformation of a symmetrical configuration, however, may lead to the new converter configurations as demonstrated by the duality between the buck-boost and Cuk converter (Fig. 7). Still in some special cases, such as a single-inductor Ćuk converter, duality transformation of a symmetrical configuration results in the same topology, which is indeed irvariant under the duality transformation. 


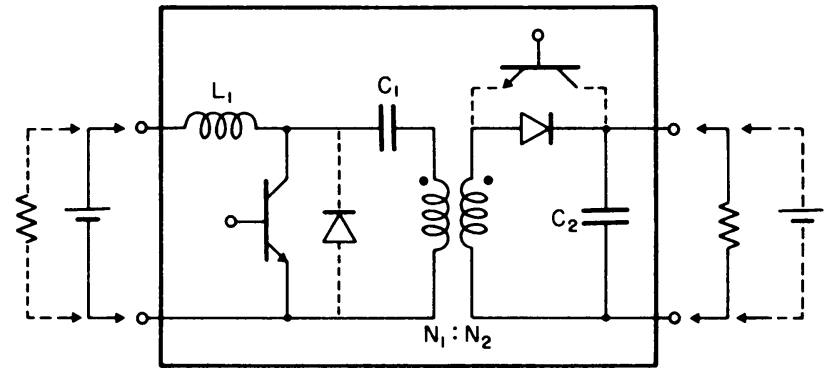

Fig. 26 Source and load interchange (dotted lines) or inversion results in the viable switching converter configuration

\section{DUALITY IN SWITCHING REGULATORS}

Very often the switching dc-to-dc converters are only a part of a larger, more complex system-the switching regulator, which through the closedloop feedback regulates the output quantity (voltage or current) despite the source and/or load variations. Duality relationships developed so far for switching converters, can now be naturally extended to switching regulators as illustrated in Fig. 27. To the switching voltage

a) switching voltage regulator

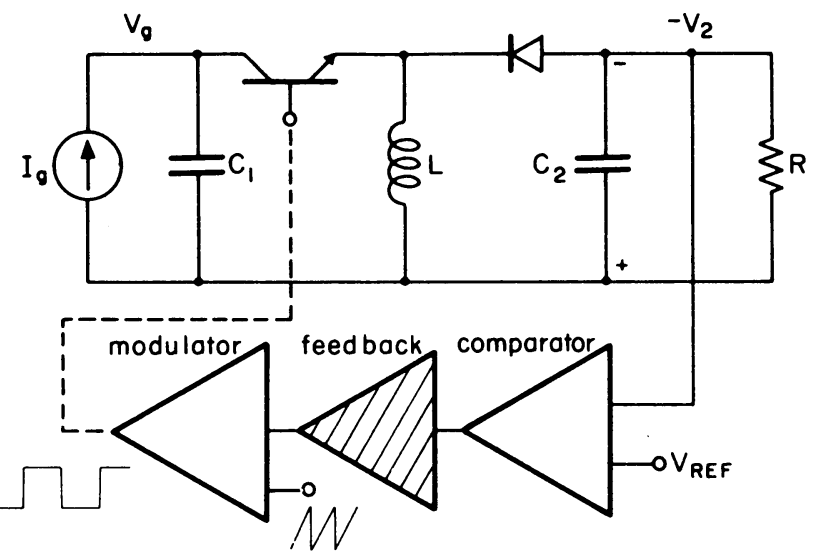

b) switching current regulator

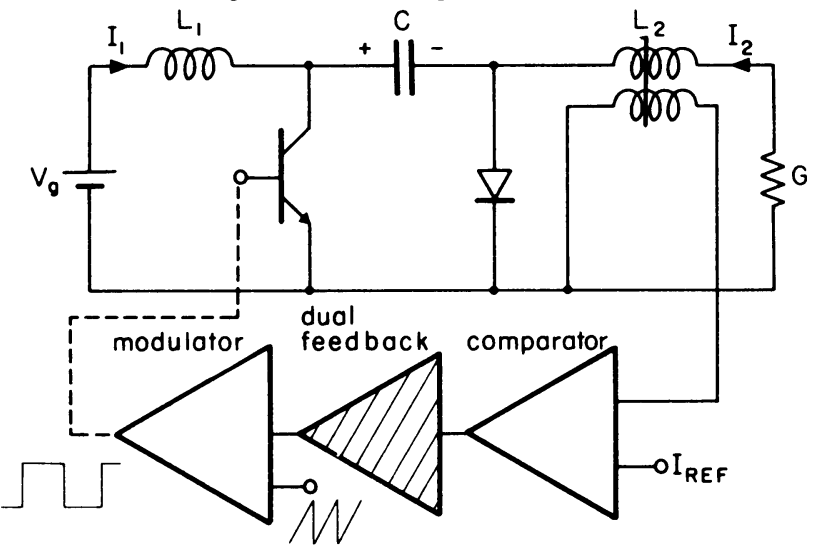

Fig. 27 Duality between the switching voltage regulator (a) and switching current regulator (b) extends even to the duality of their feedback compensation networks regulator around the buck-boost current converter (Fig. 27a) there corresponds its dual switching current regulator (Fig. 27b) built around the Cuk voltage converter. Note that in Fig. 27b the extra winding at the output only symbolically signifies that the output dc current is sensed (hence straight line across both windings) not in any way representation of the actual implementation. In the particular case, for example, sensing of the diode current by a current transformer and rectifying it results in a proper measure of the output dc current [21].

Duality relationships now extend to the overall system. If the switching voltage regulator of Fig. 27a is made stable by certain feedback compensation scheme (shaded box in Fig. 27a), the dual regulator of Fig. $27 \mathrm{~b}$ will also become stable, when the dual feedback scheme is employed. In fact, even the complete performance properties (phase margin, audio susceptibility or line rejection characteristic etc.) may be concluded on the basis of the known properties of its dual regulator.

\section{CONCLUSION}

Duality and duality relationships have been recognized and used to great advantages in many different fields: in abstract algebra and graph theory, in optimization problems (minimization of linear or nonlinear function of several variables subject to equality or even inequality constraints), just to name a few. However, in the Power Electronics field, which is perhaps the most natural ground for its application, the potential of the powerful duality concept has not been recognized in the past and duality was completely neglected. This is now corrected by establishing the duality of electric networks as the most general and fundamental correlation among the switching topologies in the Power Electronics field.

On the particular example of switching dc-todc converters, the duality is first established among the four basic switching converter configurations and then easily extended to a number of their derivatives or special cases. Several other examples are included, with no attempt for completeness. In fact, it is expected that the outlined general deductive path will be instrumental in discovering other as yet unknown converter topologies by the application of duality transformation to the existing converter configurations. For example, from the family of current-fed converters the family of voltage-fed converters could be obtained, and duality applied to more complicated and complex switching structures.

Many benefits and new results are obtained once the duality relationships are recognized. Specifically, by use of the powerful duality principle all properties and results found to be true for one converter, can be transferred into corresponding dual properties of the dual converter, and not only qualitative, but quantitative results also obtained. This then cuts in half the number of switching converters topologies needed for detailed 
quantitative study of their comparative performance since the other half is directly accountable through duality transformation.

This investigation of dual properties culminated in discovery of the new mode of switching converter operation, termed discontinuous capacitance voltage mode which was shown to be completely analogous to the usual discontinuous inductor current mode in inductive energy transfer converters.

It is demonstrated that the duality concept is applicable not only to the steady-state (dc) properties of switching converters, but to their dynamic (ac small signa1) properties, through the duality of their equivalent circuit models for both conduction modes. In particular, in the continuous conduction mode, the topological structure invariant under the duality transformation resulted in a fixed topology equivalent circuit model, the so called canonical circuit model, which has been independently obtained earlier [2]. Therefore, the modelling and analysis of switching converters and topological investigations of switching structures are finally unified into a harmonious structure.

It is expected that the concept of duality developed here for switching dc-to-dc converters, can be easily extended to functionally different but still switching structures such as $d c-t a-d c$ inverters and/or power amplifiers [22]. It is therefore believed that the duality will be used in the future to generate new, more efficient switching converter, inverter and power amplifier configurations, exhibiting overall improved performance.

\section{REFERENCES}

[1] R. Haynes, T. Phelps, J. Collins, and R. D. Middlebrook, "The Venable Converter: A New Approach to Power Processing," IEEE Power Electronics Specialists Conference, 1976 Record, pp. 92-103, (IEEE Publication 76CH1084-3 AES).

[2] Slobodan Ćuk, "Modelling, Analysis, and Design of Switching Converters, " $\mathrm{PhD}$ thesis, California Institute of Technology, November 1976. Also, NASA Report CR-13514.

[3] Slobodan Ćuk and R. D. Middlebrook, "A New Optimum Topology Switching Dc-to-Dc Converter," IEEE Power Electronics Specialists Conference, 1977 Record, pp. 160-179 (IEEE Publication $77 \mathrm{CH}$ 1213-8 AES).

[4] A. H. Weinberg, "A Boost Regulator with a New Energy Transfer Principle," Proceedings of the Spacecraft Power Conversion Electronics Seminar, September 1974, ESRO Publication SP-103.

[5] R. P. Massey and E. C. Snyder, "High Voltage Single-Ended Dc-Dc Converter," IEEE Power Electronics Specialists Conference, 1977 Record, pp . 156-159.
[6] R. P. Severns, "A New Current-Fed Converter Topology," IEEE Power Electronics Specialists Conference, 1979 Record.

[7] Slobodan Ćuk and R. D. Middlebrook, "Dc-to-Dc Switching Converter," U.S. Patent Application S.N837,532 filed September 28, 1977. Also filed in foreign countries.

[8] C. Desoer and E. Kuh: "Basic Circuit Theory," McGraw Hil1, 1969.

[9] Balabanian and Bickart: "Electrical Network Theory," John Wiley \& Sons, 1969.

[1:] R. D. Middlebrook and Slobodan Cuk, "Isolation and Multiple Output Extensions of a New Optimum Topology Switching Dc-to-Dc Converter," IEEE Power Electronics Specialists Conference, 1978 Record, pp. 256-264 (IEEE Publication 78CH1337-5 AES).

[11] Slobodan Ćuk and R. D. Middlebrook, "CoupledInductor and Other Extensions of a New Optimum Topology Switching Dc-to-Dc Converter," IEEE Industry Applications Society Annual Meeting, 1977 Record, pp. 1110-1126 (IEEE Publication 77CH1246-8-IA).

[12] Slobodan Cuk, "Switching Dc-to-Dc Converter with Zero Input or Output Current Ripple," IEEE Industry Applications Society Annual Meeting, 1978 Record, pp. 1131-1146, (IEEE Publication 78CH1346-6IA) .

[13] G. E. Bloom and A. Eris, "Practical Design Considerations of a Multi-Output Ćuk Converter," IEEE Power Electronics Specialists Conference, 1979 Record.

[14] Slobodan Ćuk and R. D. Middlebrook, "DC-toDC Conyerter Haying Reduced Ripple Without Need For Adjustments," U.S. Patent Application, June 15, 1979.

[15] Slobodan Cuk, " Dc-to-Dc Switching Converter With Zero Input and Output Current Ripple and Integrated Mangetics Circuits," U.S. Patent Application, March 30, 1979.

[16] Slobodan Cuk, "Discontinuous Inductor Current Mode in the Optimum Topology Switching Converter," IEEE Power Electronics Specialists Conference, 1978 Record, pp. 105-123 (IEEE Publication 78CH1337-5 AES).

[17] G. W. Wester and R. D. Middlebrook, "LowFrequency Characterization of Switched Dcto-Dc Converters," IEEE Power Processing and Electronics Specialists Conference, 1972 Record, pp. 9-20 (IEEE Publication 72 CHO 652-8 AES); also IEEE Trans. Aerospace and Electronic Systems, vol. AES-9, pp. 376-385, May 1973. 
[18] R. D. Middlebrook and Slobodan Cuk, "A General Unified Approach to Modelling Switching-Converter Power Stages, " IEEE Power Electronics Specialists Conference, 1976 Record, pp. 18-34, (IEEE Publication

76CH1084-3 AES); also International J. of Electronics, vol. 42, no. 6, pp. 521-550, June 1977.

[19] R. D. Middlebrook and Slobodan Ćuk, "Modelling and Analysis Methods for Dc-to-Dc Switching Converters," invited review paper, IEEE International Semiconductor Power Converter Conference, 1977 Record, pp. 90-111 (IEEE Publication 77CH1183-3IA).

[20] Slobodan Ćuk and R. D. Middlebrook, "A Genera1 Unified Approach to Modelling Switching Dc-toDc Converters in Discontinuous Conduction Mode," IEEE Power Electronics Specialists Conference, 1977 Record, pp. 36-57, (IEEE Publication $77 \mathrm{CH}$ 1213-8 AES).

[21] R. D. Middlebrook, Slobodan Cuk, and W. Behen, "A New Battery Charger/Discharger Converter," IEEE Power Electronics Specialists Conference, 1978 Record, pp. 251-255 (IEEE Publication 78CH1337-5 AES).

[22] Slobodan Cuk and Robert W. Erickson, "A Conceptually New High-Frequency Switched-Mode Amplifier Technique Eliminates Current Ripple," Proc. Fifth National Solid-State Power Conversion Conference (Powercon 5), Pp. G3.1-G3.22, May 1978 . 